\title{
Genomics-assisted prediction of salt and alkali tolerances and functional marker development in apple rootstocks
}

Jing Liu, Fei Shen, Yao Xiao, Hongcheng Fang, Changpeng Qiu, Wei Li, Ting Wu, Xuefeng Xu, Yi Wang, Xinzhong Zhang ${ }^{*}$ and Zhenhai Han

\begin{abstract}
Background: Saline, alkaline, and saline-alkaline stress severely affect plant growth and development. The tolerance of plants to these stressors has long been important breeding objectives, especially for woody perennials like apple. The aims of this study were to identify quantitative trait loci (QTLs) and to develop genomics-assisted prediction models for salt, alkali, and salt-alkali tolerance in apple rootstock.

Results: A total of 3258 hybrids derived from the apple rootstock cultivars 'Baleng Crab' (Malus robusta Rehd., tolerant) $\times$ 'M9' (M. pumila Mill., sensitive) were used to identify 17, 13, and two QTLs for injury indices of salt, alkali, and salt-alkali stress via bulked segregant analysis. The genotype effects of single nucleotide polymorphism (SNP) markers designed on candidate genes in each QTL interval were estimated. The genomic predicted value of an individual hybrid was calculated by adding the sum of all marker genotype effects to the mean phenotype value of the population. The prediction accuracy was $0.6569,0.6695$, and 0.5834 for injury indices of salt, alkali, and salt-alkali stress, respectively. SNP182G on MdRGLG3, which changes a leucine to an arginine at the VWFA-domain, conferred tolerance to salt, alkali, and salt-alkali stress. SNP761A on MdKCAB, affecting the Kv_beta domain that cooperated with the linked allelic variation SNP11, contributed to salt, alkali, and salt-alkali tolerance in apple rootstock.

Conclusions: The genomics-assisted prediction models can potentially be used in breeding saline, alkaline, and saline-alkaline tolerant apple rootstocks. The QTLs and the functional markers may provide insight for future studies into the genetic variation of plant abiotic stress tolerance.
\end{abstract}

Keywords: Saline tolerance; alkaline tolerance, QTL mapping, Malus ssp., Genetic variation

\section{Background}

Saline and alkali stress seriously affect growth, development, and plant survival. Excessive salt disturbs the ion balance in soil, causing ion toxicity and osmotic stress, thus affecting plant growth [1-3]. Alkaline stress, such as $\mathrm{Na}_{2} \mathrm{CO}_{3}$, can cause more damage to plants than neutral salts [4-6] because under alkaline stress, plants have to withstand the same osmotic stress and ion toxicity as salt stress, as well as high pH stress [7-10]. Natural salt

\footnotetext{
*Correspondence: zhangxinzhong999@126.com

College of Horticulture, China Agricultural University, Beijing, China
}

stress often occurs as mixed salt stress with both neutral and alkaline salts. Soil salinization and alkalization frequently co-occur, causing much severe problems [11]. The effects of salt-alkali stress may be more severe than any other abiotic stressor [7, 12-14].

Compared to the comprehensive soil control and optimized regionalization of farming, the most cost-efficient strategy for coping with the stress is breeding and utilizing high saline and alkali tolerant cultivars $[15,16]$. Hence understanding the inheritance and genetics of the

C C The Author(s). 2020 Open Access This article is licensed under a Creative Commons Attribution 4.0 International License, which permits use, sharing, adaptation, distribution and reproduction in any medium or format, as long as you give appropriate credit to the original author(s) and the source, provide a link to the Creative Commons licence, and indicate if changes were made. The images or other third party material in this article are included in the article's Creative Commons licence, unless indicated otherwise in a credit line to the material. If material is not included in the article's Creative Commons licence and your intended use is not permitted by statutory regulation or exceeds the permitted use, you will need to obtain permission directly from the copyright holder. To view a copy of this licence, visit http://creativecommons.org/licenses/by/4.0/. The Creative Commons Public Domain Dedication waiver (http://creativecommons.org/publicdomain/zero/1.0/) applies to the data made available in this article, unless otherwise stated in a credit line to the data. 
saline and alkali tolerances is a prerequisite of modern breeding practices [17].

Salt and alkali tolerance are partially independent traits, salt-tolerant varieties are not necessarily highly alkali-tolerant. Tolerances to salt and alkali stress are quantitative traits controlled by a few major genes and several minor genes [18-20]. The heritability of salt stress tolerance depends on the species and cultivar, ranging from $38.18 \% \sim 66.64 \%$ in lentil (Lens culinaris M.) to $75 \% \sim 83.1 \%$ in tomato (Solanum lycopersicum L.) and upland cotton (Gossypium hirsutum L.) [21-23]. Numerous quantitative trait loci (QTLs), including some major QTLs, associated with salinity tolerance trait have been identified in rice (Oryza sativa L.), tomato, Arabidopsis thaliana L., and cotton [24-27]. Similarly, numerous minor and a few major QTLs for alkali tolerance were mapped in crops [28, 29]. However, there are only a few QTLs overlapping between salt and alkali stress tolerance, $83.3 \%$ of which were independent of each other. This indicates that the genetic control of the tolerance to these two stressors might be partially independent.

Diagnostic or functional markers, designed on the functional gene body or the promoter region, can be accurately used in marker assisted selection (MAS). Therefore, many studies have been conducted to predict candidate genes from QTL confident intervals and to test the molecular functions of the genetic variations [30-34]. For example, nonsynonymous single nucleotide polymorphisms (SNPs) of GhGPAT16 and GhGPAT26 in cotton were significantly correlated with cotton oil content under salt stress [35]. A T/C SNP at TaCRT-D plays an important role in the salt tolerance of wheat (Triticum aestivum L.) [36].

When a trait is controlled by a few loci with major effects and is less affected by environmental factors, MAS is a cost-efficient strategy for selecting appropriate genotype combinations $[37,38]$. In contrast, many agronomic traits, such as salt and alkali tolerance, are often affected by polygenes with minor effects. In this scenario, genomic selection (GS) should be an effective alternative [39-41]. GS explores the contribution of whole genome markers for a certain trait, but the cost of GS is high because it requires a larger population size and higher marker density [42]. Fully utilizing QTL-based markers in GS modeling might be a solution for addressing the cost-efficiency of GS [38].

The aims of this study were to identify genome-wide QTLs associated with tolerance to salt, alkali, and combined salt-alkali stress, and to develop QTL-based genomics-assisted prediction (GAP) models in apple rootstocks. A bulked segregant analysis via next generation resequencing (BSA-seq) was used for QTL detection. Then, the effects of each QTL-based marker were estimated and GAP models were developed and validated. The GAP models obtained in this study can assist breeding for salt and alkali stress tolerance in asexually propagated perennial crops such as apple.

\section{Results}

Phenotype segregation and analysis of inheritance

By using leafy cutting propagated plants of F1 hybrids from Malus robusta Rehd. 'Baleng Crab (BC)' $\times M$. pumila Mill. 'M9', salt injury index (SID), alkali injury index (AID), and salt-alkali injury index (SAID) were phenotyped in 2015-2017. The phenotype exhibited broad segregation ranging with averages of $0.46,0.48$, and 0.57 for SID, AID, and SAID, respectively (Fig. 1a; Fig. S1; Table 1; Table S1, S2, S3). The overall mean phenotype value of the population for SID, AID, and SAID was approximately equal to that of to their midparent value, respectively (Table 1). The segregation spectrums were nearly Gaussian distributed (Fig. S1). The broad sense heritability of SID, AID, and SAID was $63.28,62.26$ and $60.69 \%$, respectively (Table 1 ).

The Pearson's correlation coefficient was $0.1474(p<$ 0.05) between SID and AID, indicating a weak positive correlation. The Pearson's correlation coefficient between SID and SAID was $-0.0172(p>0.1)$. For AID and SAID, the Pearson's correlation coefficient was $0.1959(p<0.01)$ (Fig. 1c), indicating a negative correlation between AID and SAID. We found that not all of the salt-tolerant plants were alkali-tolerant, while saltsensitive plants were not necessarily all alkali-sensitive (Fig. 1b).

\section{Identification of QTLs via BSA-seq}

Based on the phenotyping data from 2015 to 2017, six segregant bulks were developed, each including 11-26 hybrids with extreme phenotypes for tolerance or sensitivity to salt, alkali, or salt-alkali stress (Fig. 2a; Table S4). Sequencing of the six bulk DNA samples generated a total of $611,037,786$ clean reads, of these reads, $97.77 \%$ were mapped to the apple 'Golden Delicious' dihaploid GDDH genome and $74.54 \%$ were uniquely mapped (Table S5). Seventeen QTLs for SID were mapped on chromosomes $2,7,11,14,15$, and 16 using BSATOS software [43]. This included three QTLs with large G' values, S-M02.1, S-BC15.1, and S-H16.1 (Fig. S2). For AID, 13 QTLs were identified, and the G' value of ABC09.1, A-M06.1, and A-M16.1 were greater than the other 10 QTLs (Fig. S3). Only two QTLs were detected to be associated with SAID, and the G' value of SABC16.2 was relatively large (Fig. S4). Among these QTLs, S-H16.1, A-M16.1, and SA-BC16.2 on chromosome 16 overlapped each other (Fig. 2b); QTLs A-M02.1, SM02.3, and S-H02.1 on chromosome 2 were partially overlapping (Table S6). 


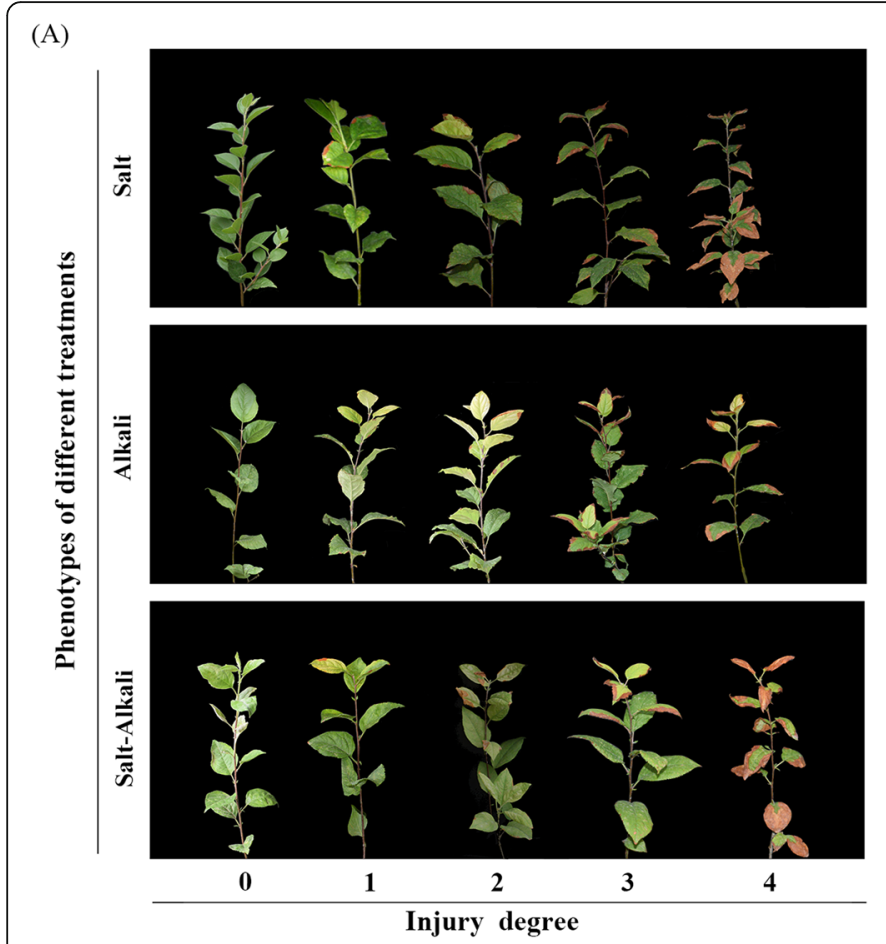

(B)
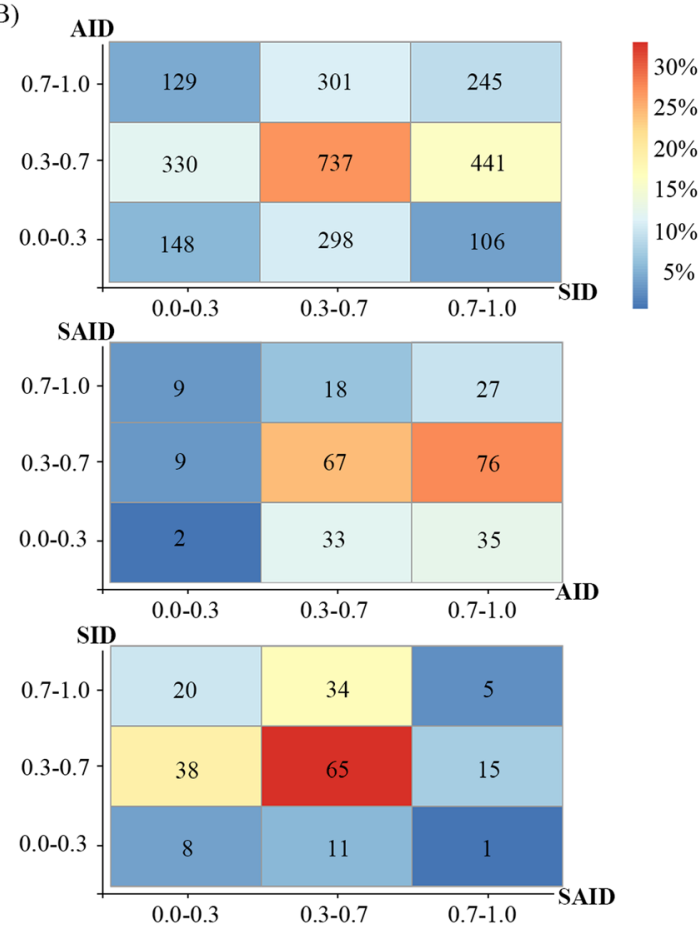

(C)
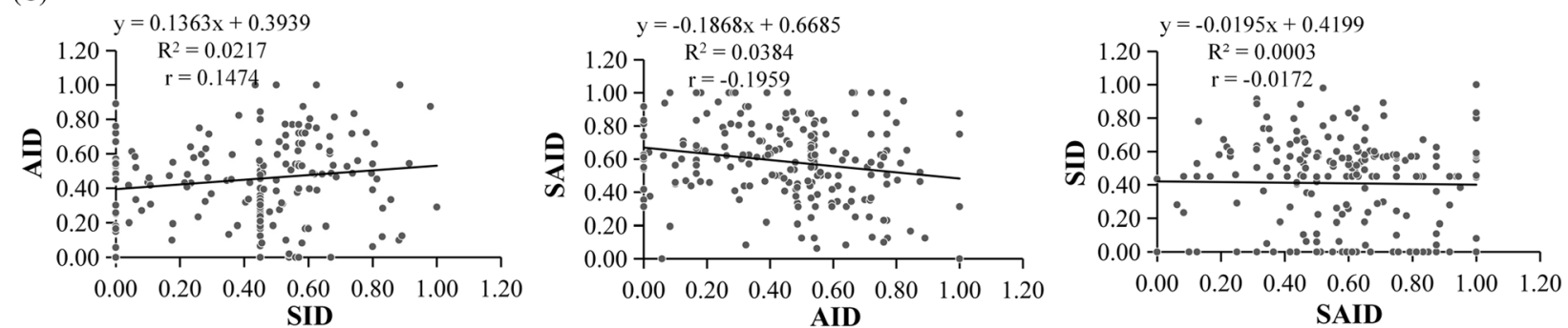

Fig. 1 Categorical criteria of injury indices and pairwise relationship between injury indices of salt (SID), alkali (AID), and salt-alkali (SAID) stress in apple rootstock hybrids of Malus robusta Rehd. 'Baleng Crab' $\times$ M. pumila Mill. 'M9'. a Photograph showing scoring criteria of injury degrees of salt, alkali, and salt-alkali stress. $\mathbf{b}$ Heatmap showing the pairwise relationship between numbers of hybrids tolerant or sensitive to salt, alkali, and saltalkali stress. The number of hybrids are presented in the blocks and the percentage of hybrids by column is illustrated by color gradients. $\mathbf{c}$ Linear regressions between $\mathrm{SID}, \mathrm{AID}$, and SAID

Table 1 Phenotype segregation and inheritance of salt, alkali, salt-alkali injury indices in apple rootstock hybrids of Malus robusta Rehd. 'Baleng Crab' $\times$ M. pumila Mill. 'M9'

\begin{tabular}{llllll}
\hline Trait & Year & Phenotype mean & Standard deviation & Coefficient of variance & Broad sense heritability \\
\hline Salt injury index & 2015 & 0.53 & 0.28 & $52.08 \%$ & $63.28 \%$ \\
& 2016 & 0.40 & 0.28 & $69.05 \%$ & $63.79 \%$ \\
Alkali injury index & 2017 & 0.43 & 0.28 & $49.17 \%$ & $56.41 \%$ \\
& 2015 & 0.51 & 0.25 & $52.98 \%$ & $62.26 \%$ \\
Salt-alkali injury index & 2016 & 0.46 & 0.26 & $42.67 \%$ & $60.69 \%$ \\
& 2017 & 0.46 & 0.24 & $46.91 \%$ & \\
\hline
\end{tabular}




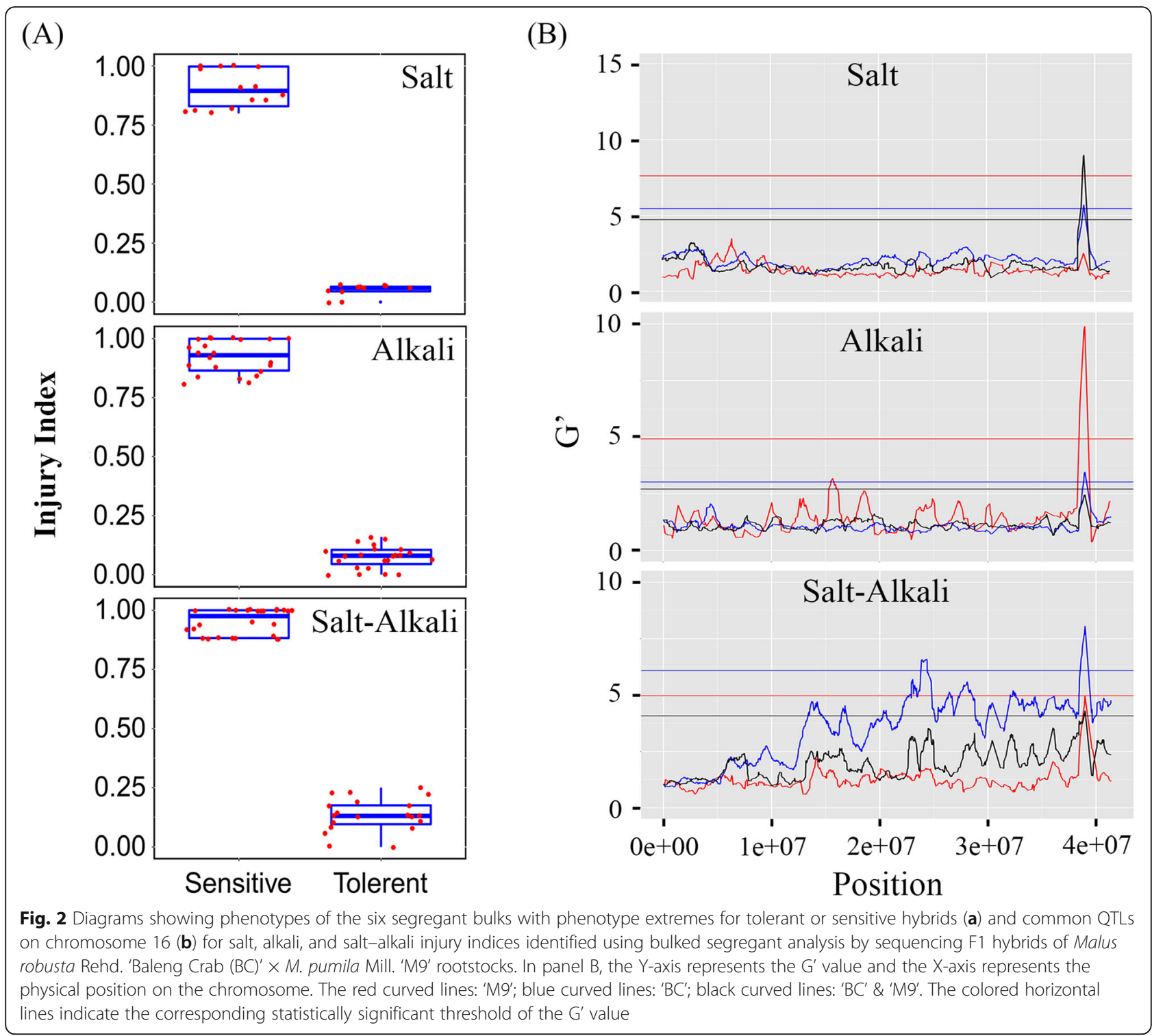

\section{Candidate gene prediction via parental resequencing data}

DNA sequences of 2657 genes within the 32 QTL intervals were downloaded from the apple 'Golden Delicious' dihaploid GDDH genome database, and then the gene expression was analyzed using RNA-seq data. Of the total number of genes, 199 were excluded because they did not show expression. Another 410 genes were culled because the genetic variations were inconsistent with the parent from which the QTL was mapped. We also excluded 883 genes for which functional annotation was not related to the targeted trait. In addition, 475 genes with variations on the promoter region but absent from the list of differentially expressed genes (DEGs) were excluded. Finally a total of 425, 248, and 17 candidate genes were predicted for SID, AID, and SAID, respectively (Table S7, S8).

RNA-seq analysis for salt, alkali, and salt-alkali tolerances

To show the differences in gene expression between hybrids that were tolerant or sensitive to salt, alkali, and salt-alkali stress, RNA-seq was performed. RNAseq generated 289.94 Gb clean data with a Q30 value of 92.85. For each sample, over 3.04 Gb clean reads were generated, with an average GC content of $46.93 \%$. The average proportion of total reads mapped to the reference genome was $86.05 \%$ (Table S9, S10, S11). A total of 875, 658, and 5359 DEGs were identified between hybrids which were tolerant/sensitive to salt, alkali, and salt-alkali, respectively (Table S12, S13, S14). 
The expression profiles differed among salt, alkali, and salt-alkali stress tolerant hybrids compared to sensitive hybrids. The expression of most abscisic acid (ABA) signaling related genes were lower throughout the experiment in saline or alkaline sensitive hybrids; some ABA related genes were considerably higher in salt-alkali sensitive hybrids compared to the other hybrids (Fig. 3a-c). Conversely, the transcription of genes related to secondary metabolites were upregulated in saline and alkaline sensitive hybrids (Fig. 3a and c). In salt or salt-alkali tolerant hybrids, the expression of nearly all the abiotic stress response genes were higher, but most ethylene biosynthesis or signaling genes were expressed at lower levels (Fig. 3a and c). A large proportion of cell wall associated genes had a greater level of expression in alkali and salt-alkali sensitive hybrids (Fig. $3 \mathrm{~b}$ and c). Most jasmonate (JA) related genes were highly expressed in alkali sensitive hybrids, while exhibited upregulation in salt-alkali sensitive hybrids (Fig. 3b and c).

To test the interaction among DEGs, the coexpression network was analyzed. The majority of DEGs responded at early stage (day $0-4$ ) to salt stress than to alkali (at day 4) or salt-alkali stress (at day 3) (Fig. 4). A GATA transcription factor (TF) gene, MD16G1234900, and several ubiquitin related genes co-expressed with DEGs in tolerant to salt, alkali, and salt-alkali hybrids compared to sensitive hybrids (Fig. 4; Table S15). MD16G1234900 was located in the confident interval of QTL SA-BC16.1 (Table S8). Similarly, 13 transcription factors co-expressed with a group of DEGs between hybrids that were tolerant to saline or alkaline stress (Fig. 4; Table S15). In response to salt stress, a specific co-expression network was found to include a GATA12 gene
(MD15G1092500) and several heat shock protein genes. Another co-expression network of 29 DEGs responded to alkaline stress (Fig. 4; Table S15). MD16G1235900, a voltage-gated potassium channel subunit beta gene $M d K C A B$, also located within QTL SA-BC16.1 interval, co-expressed with DEGs of saline-alkaline tolerant hybrids (Table S8).

\section{Development of GAP models}

To develop the GAP models, a SNP was chosen from every candidate gene to design markers for kompetitive allele-specific PCR (KASP). A total of 17, 13, and two KASP markers were designed for the traits SID, AID, and SAID, respectively (Table S16).

The marker SH14275 from QTL S-H14.1 exhibited the largest marker effect (0.4235); the marker effect (0.0354) of SM1111 from QTL S-M11.1 had the least effect on SID (Table S17). For alkali tolerance, the largest marker effect (0.2134) on AID was estimated in AB1614 derived from QTL A-BC16.1, whereas marker nn174 from QTL A-M06.1 (0.0119) had the lowest marker effect (Table S17). For SAID, the effects of both the markers SAB161 and SAB162 designed on QTLs SA$\mathrm{BC} 16.1$ and SA-BC16.2, respectively, were as large as 0.2391 and 0.2947 (Table S17).

To calculate genomics predicted value (GPV), the genotype effects of all markers for SID, AID, and SAID were added to the overall value of the mean phenotype for an individual hybrid (Table S18, S19, S20). The prediction accuracy, represented by Pearson's correlation coefficients between GPV and the observed phenotype value (OPV) of individual hybrids, was $0.6569,0.6695$, and 0.5834 for SID, AID, and SAID, respectively (Fig. 5). Five-fold cross validation confirmed the accuracy of the

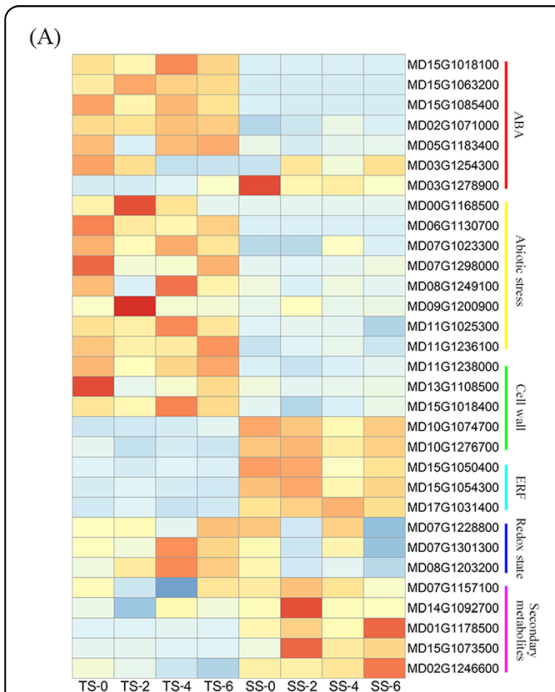

(B)

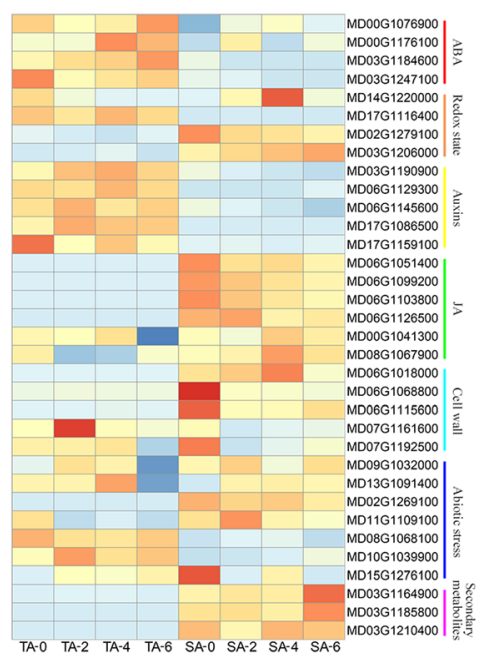

(C)

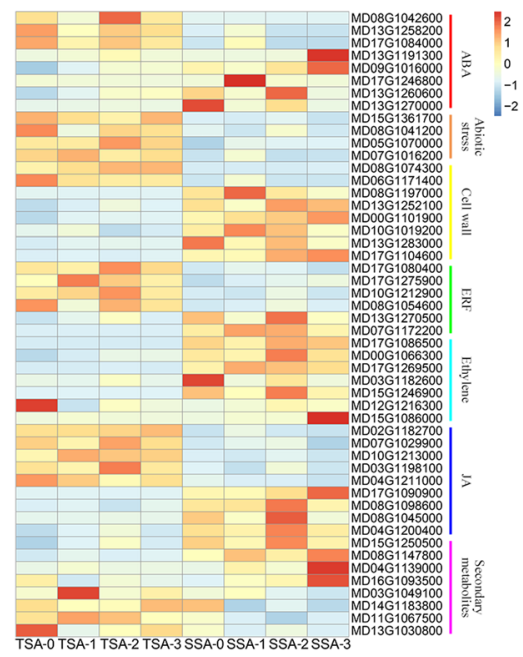

Fig. 3 Heatmaps showing differentially expressed genes between individuals that were tolerant or sensitive to salt (a), alkali (b), and salt-alkali stress (c) in F1 hybrids of Malus robusta 'Baleng Crab' $\times$ M. pumila 'M9' rootstocks 

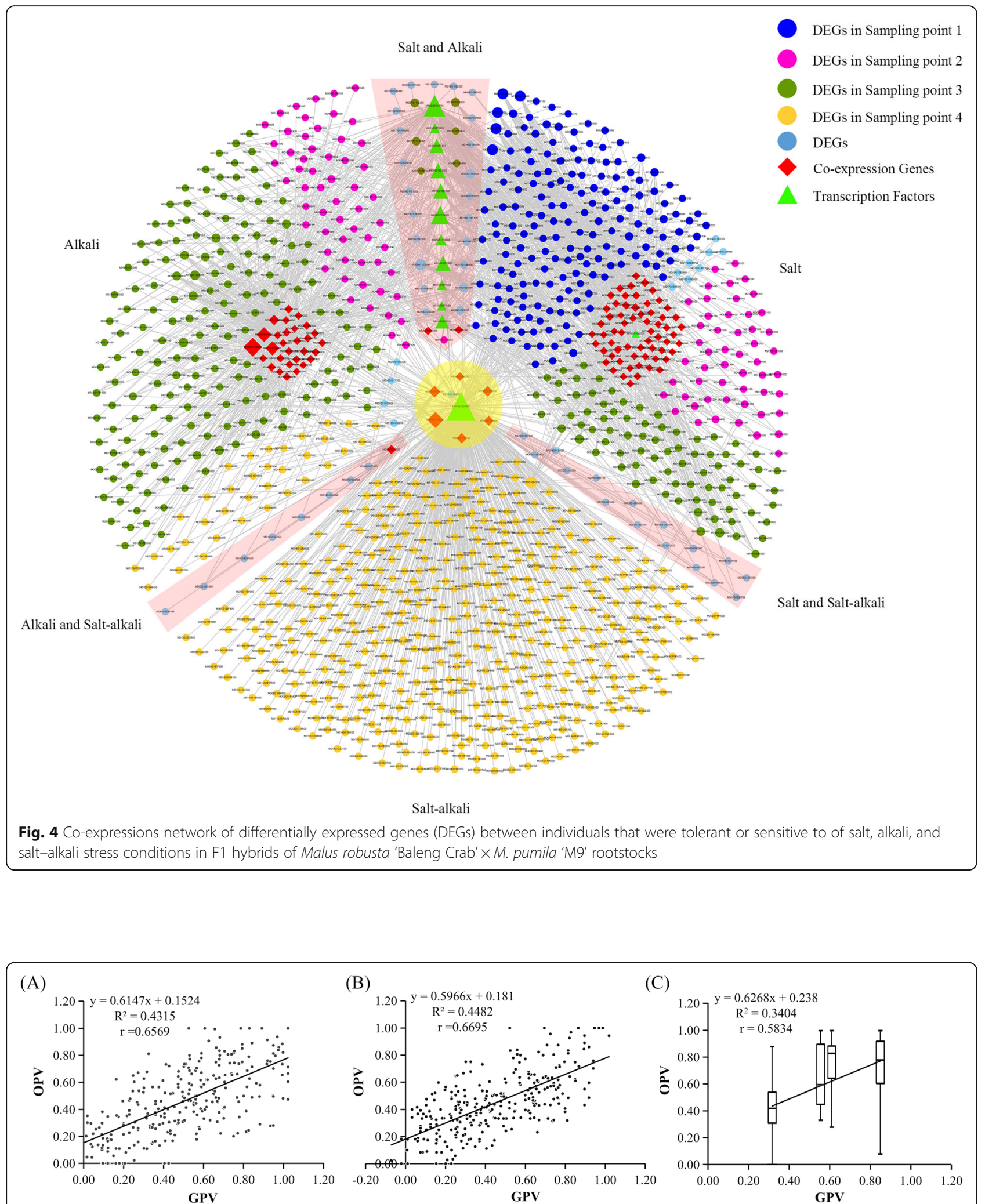

Fig. 5 Linear regression between genomics predicted value (GPV) and observe phenotype value (OPV) of injury indices of salt (a), alkali (b), and salt-alkali stress (c) in F1 hybrids of Malus robusta 'Baleng Crab' $\times$ M. pumila 'M9' rootstocks. Because there were only four genotype combinations in (c), the data dots should appeared to form four vertical lines, by which it is difficult to see how much the data are segregating, so, box plot was used to show the deviation, the mean value, and the standard variance 
predictability of GPV by $0.6587,0.6573$, and 0.6534 for SID, AID, and SAID, respectively (Table S21).

In the simulative selection, when GPV criteria were set as 0.2 , the selection rates were 16.84 and $18.06 \%$ for SID and AID, respectively (Table 2). The selection efficiencies, represented by the percentage of individuals for which OPV is consistent with the corresponding GPV, were 58.33 and $40.74 \%$ for SID and AID, respectively (Table 2). For SAID, if the GPV criterion was 0.32, the selection rate was as high as $42.78 \%$, and the selection efficiency was as relatively low as $31.33 \%$ (Table 2).

\section{Validation of functional variations in the candidate gene MdRGLG3}

From the overlapping QTLs, S-H16.1, A-M16.1, and SA-B16.2 on chromosome 16, MdRGLG3 (MD16G1282700) was predicted as a candidate gene for SAID. The full length coding sequence (CDS) of MdRGLG3 was $1107 \mathrm{bp}$, encoding an E3 ubiquitinprotein ligase with 369 amino acid residues. In the CDS of MdRGLG3, two nonsynonymous heterozygous SNPs were found at $+182 \mathrm{bp}$ (SNP182) and $+932 \mathrm{bp}$ (SNP932) from the ATG codon in the maternal parent 'BC'. SNP182 G/T may change a leucine to an arginine at the vWFA-domain; SNP932 T/C leads to an amino acid substitution of valine with alanine (Fig. 6a). Two nonsynonymous SNPs, SNP168 C/G at $+168 \mathrm{bp}$ and SNP936 G/C at +936 bp from the ATG codon, were detected in the pollen parent 'M9', causing a change from phenylalanine to leucine and from lysine to asparagine, respectively (Fig. 6a). These SNPs were then confirmed by Sanger sequencing (Fig. 6a; Fig. S5). There were $16 \mathrm{SNPs}$ and insertion/deletions (InDels) located in the $1600 \mathrm{bp}$ DNA fragment upstream of the ATG codon of MdRGLG3 in 'M9' but not 'BC' (Supplementary File 1). In the root tissue of 'BC' and 'M9,' no differences in MdRGLG3 expression were detected in fragments per kilobase per million (FPKM) by RNA-seq or in the relative expression determined by qPCR, indicating that the promoter variations did not alter the gene expression (Supplementary File 1; Fig. S6A).

To further confirm the function of the variations in MdRGLG3 CDS, the variants were transformed into apple callus. The in vitro growth of both MdRGLG3 over-expression and MdRGLG3-RNAi apple calli was similar with the untransformed wild type (WT) under normal conditions. However, the MdRGLG3-RNAi line exhibited severely less fresh weight and higher malondialdehyde (MDA) content 14 days after treatments with either salt, alkali or salt-alkali (Fig. 6b and d). After 14 days under salt, alkali, or salt-alkali stress conditions, the fresh weight of 35S:MdRGLG3$182 \mathrm{G}$ apple calli was significantly higher, whereas the MDA content was significantly lower, than the other transformants and the WT (Fig. 6c and d). The phenotype values of SID, AID, and SAID in F1 hybrids with the MdRGLG3 SNP182G allele were significantly lower than that in hybrids without the SNP182G allele (Fig. 6e). SNP182G was closely linked to the tolerance genotype of the KASP marker ABC16.1 (Table S22). These data indicated that MdRGLG3 SNP182G allele was a functional variation

Table 2 Simulative selection of salt, alkali, and salt-alkali stress tolerant individuals of apple rootstocks by genomics-assisted prediction in an F1 population derived from Malus robusta Rehd. 'Baleng Crab' $\times$ M. pumila Mill. 'M9'

\begin{tabular}{|c|c|c|c|c|c|c|}
\hline Trait & GPV criterion & Number of selections & Selection rate & GPV & Number of selections (OPV $\leq \mathrm{GPV}$ ) & Efficiency \\
\hline \multirow[t]{5}{*}{ Salt injury index } & $\leq 0.10$ & 24 & $8.42 \%$ & 0.06 & 13 & $54.17 \%$ \\
\hline & $\leq 0.20$ & 48 & $16.84 \%$ & 0.11 & 28 & $58.33 \%$ \\
\hline & $\leq 0.30$ & 74 & $25.96 \%$ & 0.16 & 35 & $47.30 \%$ \\
\hline & $\leq 0.40$ & 106 & $37.19 \%$ & 0.21 & 41 & $38.68 \%$ \\
\hline & $\leq 0.50$ & 139 & $48.77 \%$ & 0.27 & 45 & $32.37 \%$ \\
\hline \multirow[t]{5}{*}{ Alkali injury index } & $\leq 0.10$ & 23 & $7.69 \%$ & 0.05 & 13 & $56.52 \%$ \\
\hline & $\leq 0.20$ & 54 & $18.06 \%$ & 0.1 & 22 & $40.74 \%$ \\
\hline & $\leq 0.30$ & 102 & $34.11 \%$ & 0.17 & 33 & $32.35 \%$ \\
\hline & $\leq 0.40$ & 138 & $46.15 \%$ & 0.22 & 39 & $28.26 \%$ \\
\hline & $\leq 0.50$ & 174 & $58.19 \%$ & 0.27 & 42 & $24.14 \%$ \\
\hline \multirow[t]{5}{*}{ Salt-alkali injury index } & $\leq 0.12$ & 0 & $0.00 \%$ & 0 & 0 & $0.00 \%$ \\
\hline & $\leq 0.22$ & 0 & $0.00 \%$ & 0 & 0 & $0.00 \%$ \\
\hline & $\leq 0.32$ & 83 & $42.78 \%$ & 0.4142 & 26 & $31.33 \%$ \\
\hline & $\leq 0.42$ & 83 & $42.78 \%$ & 0.4142 & 26 & $31.33 \%$ \\
\hline & $\leq 0.52$ & 83 & $42.78 \%$ & 0.4142 & 26 & $31.33 \%$ \\
\hline
\end{tabular}




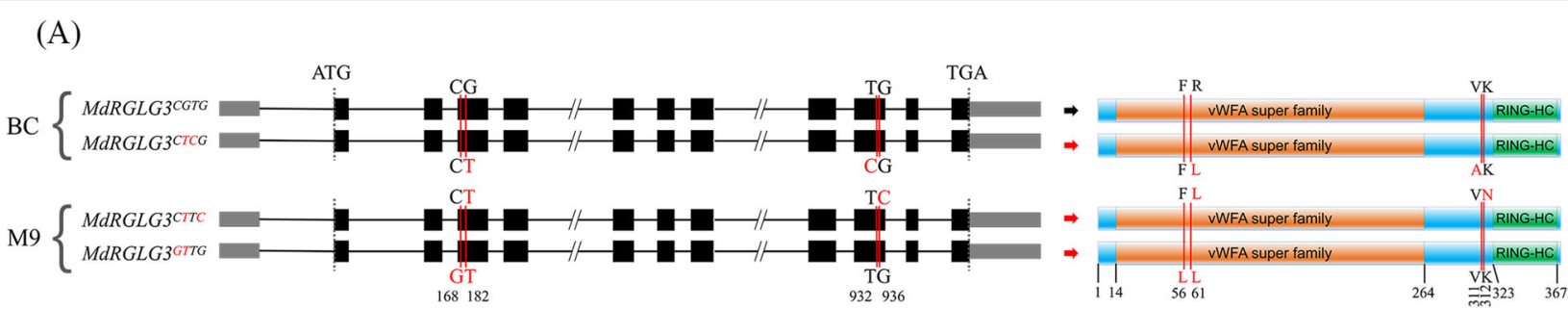

(B)
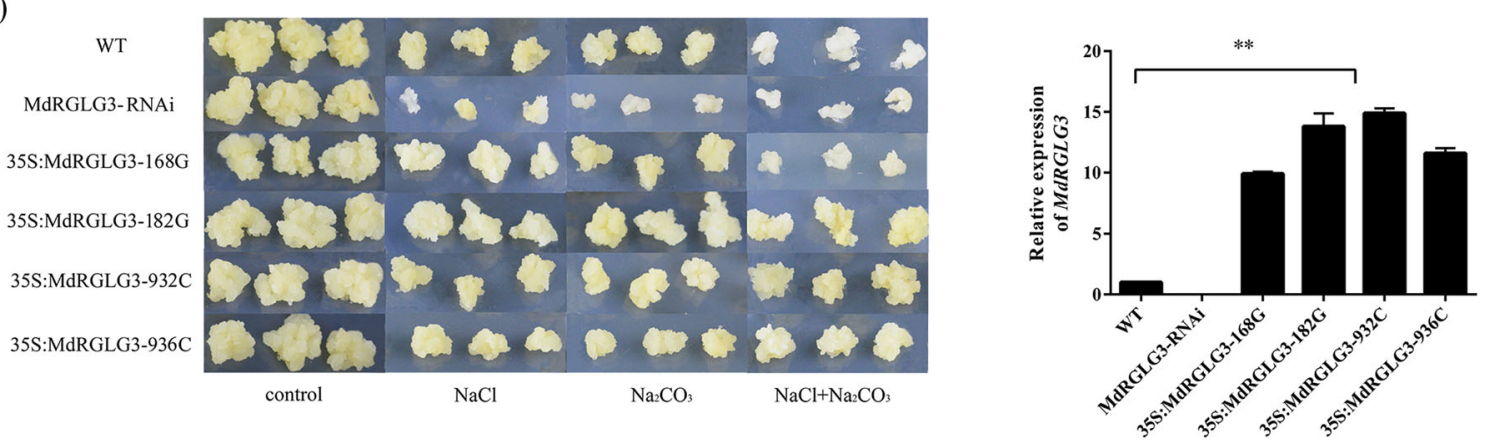

(C)

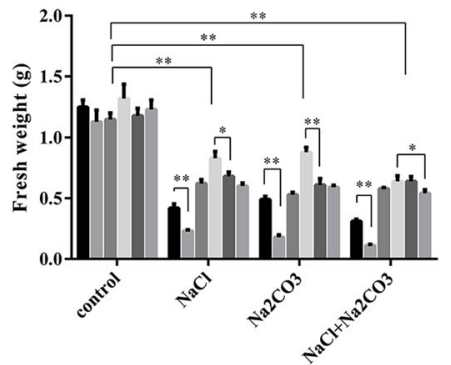

(D)

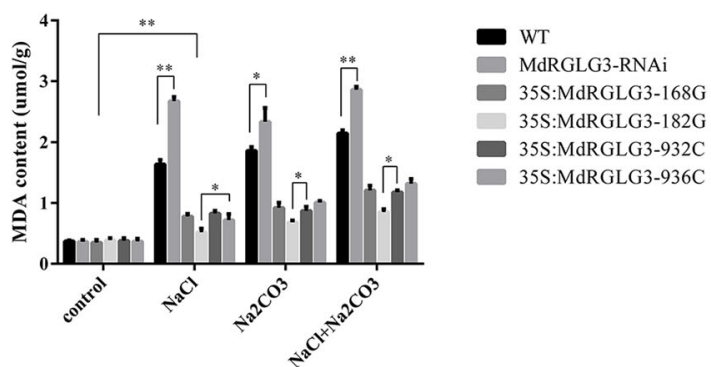

(E)
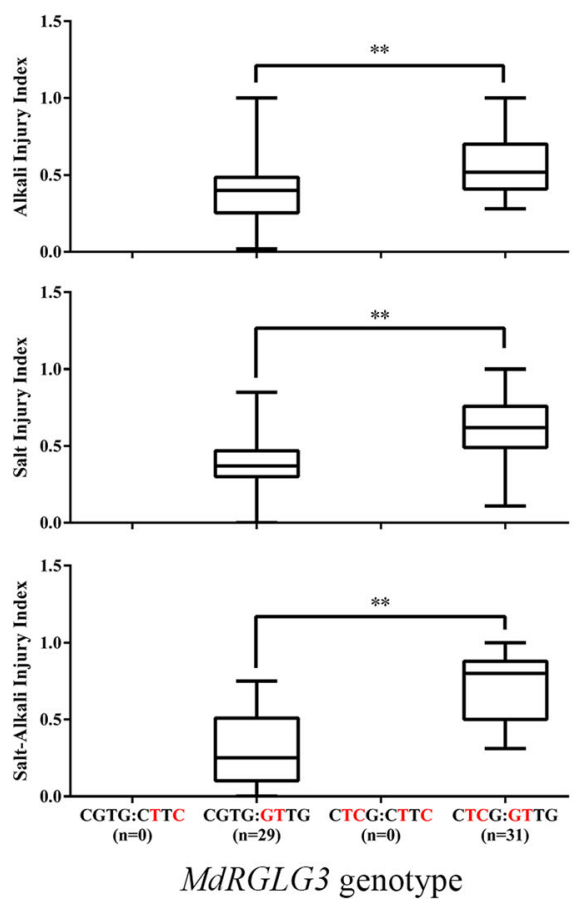

$M d R G L G 3$ genotype

Fig. 6 Schematic showing genetic variations on the coding sequence of MdRGLG3 and functional validation of these variations via callus transgenesis and genotype-phenotype association. a: Schematic diagram showing single nucleotide polymorphisms on the coding region and variations in the amino acid sequences of $M d R G L G 3$. b: Images showing in vitro growth of transformed apple callus overexpressing variants of MdRGLG3 and the MdRGLG3-RNAi line on media containing high levels of $\mathrm{NaCl}, \mathrm{Na}_{2} \mathrm{CO}_{3}$, or $\mathrm{NaCl}+\mathrm{Na}_{2} \mathrm{CO}_{3}$. C and D: Column blots showing differences in apple callus fresh weight (c) and malondialdehyde (MDA) content (d) 14 days after treatment with $\mathrm{NaCl}_{1} \mathrm{Na}_{2} \mathrm{CO}_{3}, \mathrm{or}_{\mathrm{NaCl}}+\mathrm{Na}_{2} \mathrm{CO}_{3}$, among transformants overexpressing variants of MdRGLG3 or the MdRGLG3-RNAi line. E: Box-plot showing injury indices of salt, alkali, and saltalkali stress in F1 hybrids of 'Baleng Crab' X'M9' with different genotype combinations of MdRGLG3 SNP168, SNP182, SNP932, and SNP936. Data are means \pm standard deviation of three biological replicates. ${ }^{*},{ }^{* *}$, and ${ }^{* * *}$ indicate statistically significant differences at $P<0.05, P<0.01$, and $P<0.001$, respectively

leading to increased tolerance to salt, alkali, and saltalkali conditions. One hundred Malus accessions were then genotyped for the MdRGLG3 SNP182 allele; the genotype frequency of the SNP182G:G homozygote was as low as $1 \%$, compared with 27 and $72 \%$ for SNP182G:T and SNP182T:T, respectively, indicating a 
possibly lethal effect of the SNP182G:G genotype (Table S24).

\section{Validation of functional variations in the candidate gene MdKCAB}

From QTL SA-B16.1, MdKCAB (MD16G1235900) on chromosome16 was predicted as a candidate gene for salt-alkali tolerance. The full length CDS of $M d K C A B$ was $1002 \mathrm{bp}$, encoding 334 amino acid peptide. The expression of $M d K C A B$ did not differ between the parents, 'BC' and 'M9' (Fig. S6B). No variations altering the cis-element in the $1.5 \mathrm{~kb}$ upstream region were detected in either 'BC' or 'M9' (Supplementary File 2). However, two nonsynonymous SNPs were detected at $+11 \mathrm{bp}$ and $+761 \mathrm{bp}$ from the ATG codon in 'BC' but not in 'M9' (Fig. 7a). These SNPs were confirmed by Sanger sequencing (Fig. S7). SNP11 A/ $G$ and SNP761 G/A led to a substitution from aspartic acid to serine and from arginine to lysine, respectively (Fig. 7a; Fig. S7).

Under normal conditions, transformed apple calli overexpressing $M d K C A B$ or MdKCAB-RNAi showed no difference in in vitro growth compared to the WT, irrespective of genotypes. Under salt, alkali, or salt-alkali treatments, the growth of MdKCAB-RNAi calli was significantly reduced after 14 days of culture (Fig. 7b and c). When grown under salt, alkali, or salt-alkali stress conditions, $M d K C A B$ overexpressed calli showed better proliferation and lower levels of MDA than the untransformed WT and MdKCABRNAi line (Fig. 7c and d). After 14 days of salt, alkali, or salt-alkali stress conditions, the callus transformed with 35S:MdKCAB-11G761A had a significantly higher fresh weight and lower MDA content, while other transformants had no significant difference (Fig. 7c and d). The phenotype values of SID, AID, and SAID in F1 hybrids with SNP11G/ SNP761A alleles of $M d K C A B$ were significantly lower than that of hybrids without these alleles. SNP11G761A was closely linked to the tolerance genotype of the SA-BC16.1 KASP marker (Fig. 7e, Table S23). These data indicated that SNP11G and SNP761A of $M d K C A B$ both contributed to the improved tolerance of apple rootstock to salt, alkali, and salt-alkali stress conditions.

\section{Changes in osmolality of Hoagland's solution caused by the addition of $\mathrm{NaCl}$ and/or $\mathrm{Na}_{2} \mathrm{CO}_{3}$}

The addition of $\mathrm{NaCl}$ and/or $\mathrm{Na}_{2} \mathrm{CO}_{3}$ in the nutrient solutions in alkaline, saline, and alkaline-saline stress treatments led to significant increases in osmolality of the solutions (Fig. S8). The osmolality values in the solutions for alkali $(1.75 \mathrm{MPa})$, salt $(2.73 \mathrm{MPa})$, and alkali-salt
(5.12 MPa) treatments were 2,3 , and 5 times that of non-stress control (0.82 MPa) (Fig. S8).

\section{Discussion \\ Tolerance to salt, alkali, and salt-alkali stress overlapped genetically}

Salt stress and alkali stress are usually accompanied by or closely associated with each other in environments, and plant tolerances to salt and alkali are often genetically and physiologically linked but distinct $[7-10]$. We found that the correlation between SID and AID was relatively weak. In addition, the salt-tolerant hybrids that had a low SID $(0.0 \sim 0.3)$ segregated for AID and vice versa. Of the 17, 13, and two QTLs linked to SID, AID, and SAID, S-H16.1/AM16.1/SA-BC16.2 on chromosome 16 and A-M02.1/ S-M02.3/S-H02.1 on chromosome 2 overlapped, explaining the genetic linkage of these traits. The other QTLs that did not overlap highlight the independent segregation of salt, alkali, and salt-alkali tolerances. These results were consistent with previous reports in cereal crops $[20,44,45]$. The allelic variation of MdRGLG3 due to SNP182G conferred tolerance to either salt, alkali, or salt-alkali stress. RNAseq data showed that the regulatory pathways and related DEGs under salt or alkali stress were different from those under salt-alkali stress, indicating that the mechanism of genetic diversity of these stress tolerances were not the same.

Recently, genetic network and molecular mechanism of plant stress tolerances have been increasingly explored via multi-omics strategies, such as RNAseq, QTL mapping, and co-expression tools $[43,46]$. In this study, a GATA TF gene, MD16G1234900, was identified as important candidate gene associated with salt, alkali, and salt-alkali tolerance by using co-expression analysis. Consistently, the GATA TF gene was located in the confident interval of QTL SA-BC16.1. GATA TF regulates many ubiquitin related genes that are responsive to saline or alkaline stress [47, 48]. Similarly, 13 TF genes were coexpressed with a group of DEGs related to salt or alkali tolerance (Fig. 4; Table S15). Of these TFs, ABI5 responds to stress-induced $\mathrm{ABA}$ and co-expresses with ERF10 and NHL network to regulate salt or alkali tolerance [49-51].

We detected a salt stress specific co-expression network including a series of heat shock protein genes. Plant heat stress TFs regulate responses not only to high temperatures but also to diverse environmental stresses [52-54]. HSFA4A of Arabidopsis promotes the expression of a wide range of defense genes and regulates tolerance to salinity [55]. 


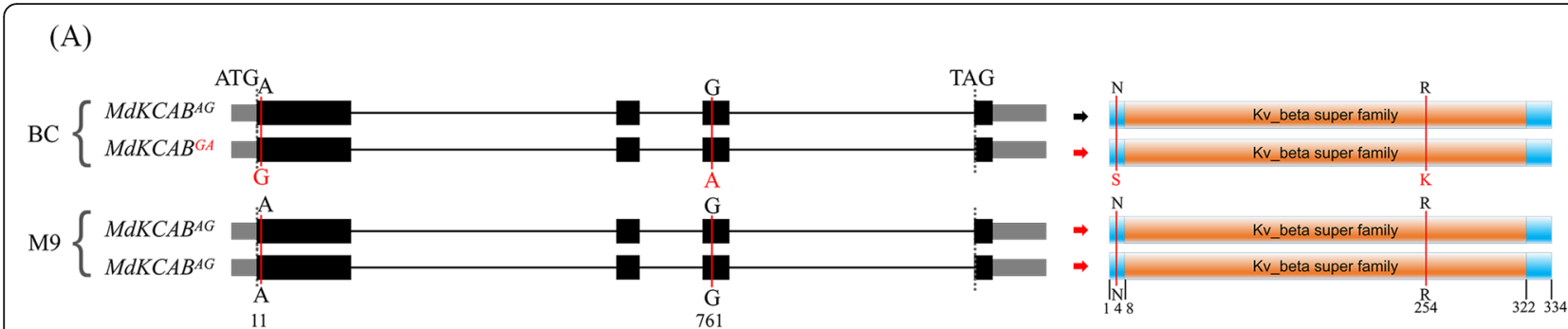

(B)
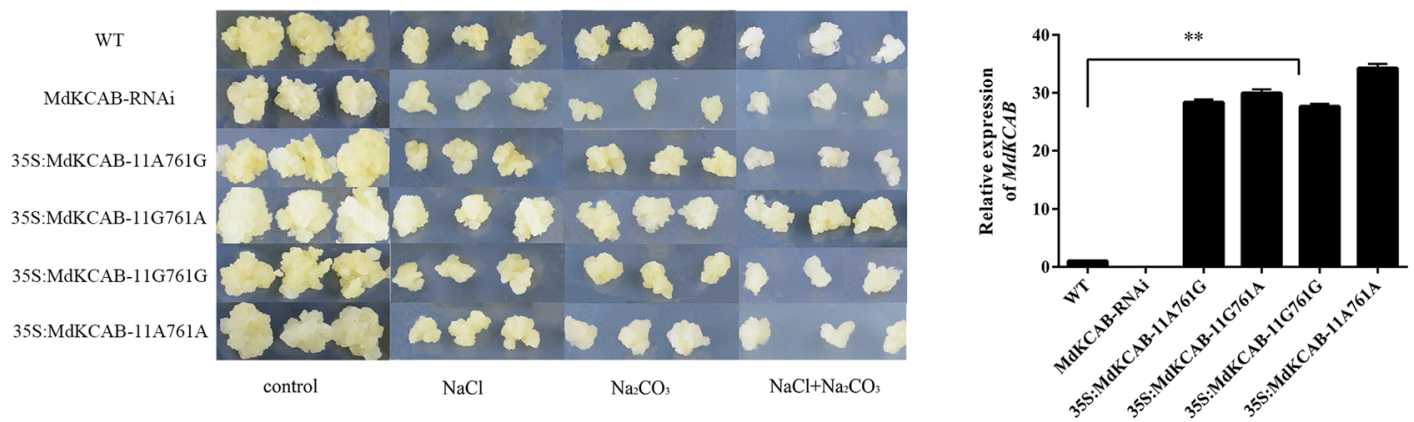

(C)

(D)
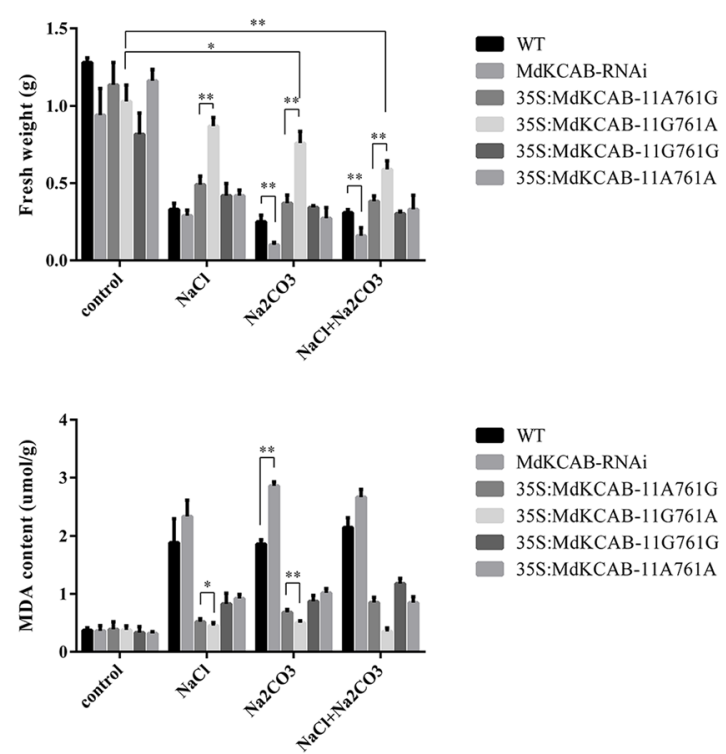

(E)
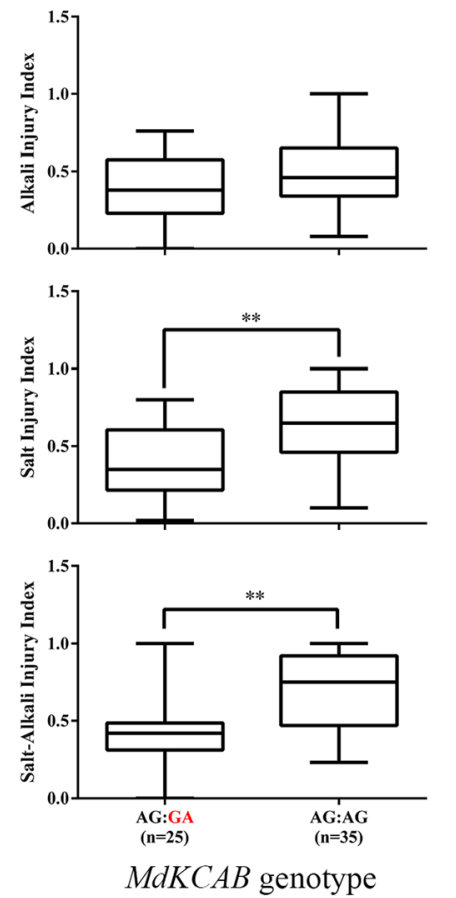

Fig. 7 Schematic diagram showing genetic variations of the coding sequence of $M d K C A B$ and the functional validation of these variations via callus transgenesis and genotype-phenotype association. a: Schematic diagram showing single nucleotide polymorphisms on the coding region and the changes in the encoded amino acids of MdKCAB. b: Images showing in vitro growth of transformed apple callus overexpressing variants of $M d K C A B$ and the MdKCAB-RNAi line 14 days after treatment with $\mathrm{NaCl}, \mathrm{Na}_{2} \mathrm{CO}_{3}, \mathrm{or} \mathrm{NaCl}+\mathrm{Na}_{2} \mathrm{CO}_{3}$. $\mathbf{c}$ and $\mathbf{d}$ : Column blots showing differences in the fresh weight of the apple callus (c) and malondialdehyde (MDA) content (d) 14 days after treatment with $\mathrm{NaCl}_{1} \mathrm{Na}_{2} \mathrm{CO}_{3}$ or $\mathrm{NaCl}+\mathrm{Na}_{2} \mathrm{CO}_{3}$ among transformants overexpressing variants of MdKCAB or the MdKCAB-RNAi line. E: Box-plot showing injury indices of salt, alkali, and salt-alkali stress in F1 hybrids of 'Baleng Crab' $\times$ 'M9' with different genotype combinations of MdKCAB SNP11 and SNP761. Data are means \pm standard deviation of three biological replicates. ${ }^{*}{ }^{* *}$, and ${ }^{* *}$ indicate statistically significant differences at $P<0.05, P<0.01$, and $P<0.001$, respectively

In this study, a unique co-expression network in response to alkaline stress was detected including 29 DEGs involved in ubiquitination signaling, oxidative stress and plant cell wall. Of these genes, RD23D is a shuttle factor for the transport of ubiquitinated substrates to the proteasome in response to salinity and abscisic acid [56]. IQM1 plays a role in the regulation of ubiquitination and ROS signaling [57]. We also found several oxidative 
stress related genes, like PLDG, ASO, and MJ1384, and cell wall associated genes, such as ABCG29, WAK3 and MCD1, co-expressed in response only to alkali stress.

\section{Osmotic stress may play an important role in salt, alkali and salt-alkali stress}

Osmotic stress is one of the major factor participating in salt and alkali induced stress pathways $[58,59]$. In this study, the osmolality of solutions for alkali, salt and salt-alkali treatments increased was significantly higher than the control, osmotic stress may be involved in all of the stressful treatments. Alkaline or saline stress-induced activation of osmotic signaling acts possibly through both ABA-dependent and ABAindependent pathways [60-62]. We found that the expression of several ABA signaling related genes was lower in salt or alkali sensitive hybrids, whereas some other genes were expressed higher in salt-alkali sensitive hybrids (Fig. 3a-c). Osmotic stress can also cause the accumulation of secondary metabolites and reactive oxygen species (ROS) [63]. The transcription of genes related to secondary metabolites were upregulated in salt and alkali sensitive hybrids (Fig. 3a and c). Cell wall biosynthesis and membrane maintaining related protein can limit cellular ROS concentration under salt stress [64]. We also found higher expression of a large proportion of cell wall associated genes in alkali and salt-alkali sensitive hybrids (Fig. $3 \mathrm{~b}$ and $\mathrm{c})$.

\section{GAP models can be cost-efficient tools for large-scale breeding}

In this study, 17 and 13 QTLs were identified for SID and AID; this is consistent with the results from cereal crops $[18,44]$. The effects of markers designed on the QTL intervals varied from 0.0354 to 0.4235 for SID and from 0.0119 to 0.2134 for AID. By estimating the genotype effects of each marker, GAP models were developed for SID, AID, and SAID to calculate GPV and to select potentially elite individuals from a hybrid population. The prediction accuracy was relatively high compared with GS for fruit quality traits in apple [42, 65, 66]. In contrast, GAP models had a low efficiency for selection of salt-alkali tolerant apple hybrids (Table 2) because there were only 29 hybrids, which SAID less than 0.32 in the population and 26 of them were selected accounted for $89.7 \%$ (Table S20). The unique advantage of these GAP models was attributed to the integration of significant QTLs with GS strategy by estimation of marker genotype effects $[37,38,67]$. The prediction accuracy for SAID was relatively low because there were only two markers used in the model. Additional QTLs and markers should be identified for SAID in the future research.
To increase the predictability of the GAP models, in this study, candidate genes were predicted within the significant intervals of QTLs assisted by parental resequencing and RNA-seq data [35, 36, 43]. The markers were designed on the CDS, promoter, or the near intergenic regions of candidate genes. By using this strategy, the linkage disequilibrium decay of these QTL-based markers may be effectively eliminated $[38,68]$. Thus the prediction accuracy of the GAP models was relatively high. However, the genetic variations on only two of these candidate genes, MdRGLG3 and $M d K C A B$, were experimentally validated, a lot of work should be carried out onwards.

\section{The MdRGLG3 SNP182G conferred tolerance to salt, alkali,} and salt-alkali stress

JA and salicylate (SA) are core micro-molecules involved in biotic and abiotic stress responses [69-71]. In Arabidopsis, RGLG3, a ring-type ubiquitin ligase gene, functions as an essential negative regulator of JA signaling in response to SA, taking a pivotal role in SA-JA antagonism [72, 73]. An allelic variation in MdRGLG3 due to SNP182G altered an amino acid in the vWFA-domain and led to an increased tolerance to salt, alkali, and salt-alkali stress in F1 hybrids of 'BC' $\times$ 'M9' apple rootstock. This functional variation was confirmed by transgenic apple calli. Similarly in Arabidopsis, rglg3 rglg4 double mutant represses wound-stunted growth and relative gene expressions [72]. We also found that MdRGLG3-RNAi apple calli were sensitive to salt, alkali, and salt-alkali stress conditions. The genotype frequency of MdRGLG3 SNP182G:G was as low as $1 \%$ in 100 Malus accessions, suggesting a possibly lethal effect of the SNP182G:G genotype.

\section{SNP11G and SNP761A of MdKCAB contributed to salt, alkali, and salt-alkali stress tolerance}

Voltage-gated potassium channels are complexes of membrane-bound, ion-conducting alpha and cytoplasmic ancillary $K C A B$ subunits. $K C A B$ interacts with specific alpha-subunits to modify their expression or kinetics [74]. A limited number of studies have been conducted on plant voltage-gated $\mathrm{K}+$ channels; therefore, knowledge about these potassium channels are lagging far behind similar studies in animals [75]. We found that the linked allelic variations of $M d K C A B$ SNP11G and SNP761A could alter an amino acid residue at the $\mathrm{Kv}_{-}$beta domain of the peptide, contributing to an increase in salt, alkali, and salt-alkali tolerance in both apple plants and transgenic calli. These results may encourage future research into this mechanism. 


\section{Conclusions}

A total of 17, 13, and two QTLs for SID, AID, and SAID, respectively, were identified. The genotype effects of these QTL-based markers were estimated and GPVs were predicted using additive GAP models. The prediction accuracy was $0.6569,0.6695$, and 0.5834 for SID, AID, and SAID, respectively. Two functional markers were developed, i.e. SNP182G on MdRGLG3 and SNP11G/SNP761A on MdRGLG3, which conferred tolerance to salt, alkali, and salt-alkali stress. The QTLs and the functional variations in candidate genes may facilitate understanding the mechanism of abiotic stress tolerance. The GAP models can potentially assist future molecular breeding in woody perennials. Still more functional markers should be developed in the onward study to improve the prediction accuracy of the GAP models.

\section{Methods}

\section{Plant materials and treatments}

All the plant materials were originally possessed by China Agricultural University. The experimental research on plants including field investigation and sample collection were performed under institutional guidelines in accordance with local legislation. A total of 3258 hybrids were used in this study. These hybrids were derived from a cross between the salt and alkali tolerant apple rootstock 'Baleng Crab (BC)'(Malus robusta Rehd.) and the salt and alkali sensitive 'M9' (M. pumila Mill.). From 2015 to 2017, at least 36 plants from each hybrid were propagated via leafy cutting and were sandcultured. The plants were drip irrigated with $1 / 2$ Hoagland's solution at a flow rate of $2 \mathrm{~L} \cdot \mathrm{h}^{-1}$. Salt, alkali, and salt-alkali stress treatments were performed for 30 days with three biological replicates (three plants per hybrid per treatment or control). The salt treatment consisted of the addition of $100 \mathrm{mM} \mathrm{NaCl}$ to $1 / 2$ Hoagland's solution; the alkali treatment consisted of $\mathrm{Na}_{2} \mathrm{CO}_{3}$ until $\mathrm{pH}=9.0$. The salt-alkali stress treatment consisted of the addition of both $100 \mathrm{mM} \mathrm{NaCl}$ and $\mathrm{Na}_{2} \mathrm{CO}_{3}$ until $\mathrm{pH}=9.0$ to the nutrient solution [76, 77]. The osmolality of the nutrient solutions was measured with Split type hygrometer (GM1361, Benetech), following the formula described previously by other authors [78]. To examine the genotype frequency of candidate genes, 100 Malus accessions were genotyped using a KASP assay. The severity of salt, alkali, and salt-alkali injury was scored as previously described (Fig. 1) [76]. The tolerance was negatively represented by SID, AID, and SAID.

\section{BSA-seq analysis}

Segregant bulks of each phenotype consisted of 11-26 hybrids, the hybrids extremely tolerant or extremely sensitive to salt, alkali, or salt-alkali stress, respectively. Genomic DNA of each hybrid was extracted, equally pooled, and sequenced using a paired-ends 150 strategy (Illumina X10, Illumina, USA). The sequencing reads were obtained and mapped to the apple 'Golden Delicious' dihaploid GDDH genome using Burrows-Wheeler Alignment software [79, 80]. A modified G' value was used for the statistical analysis of allelic variations between the two bulks $[43,81]$.

\section{RNA-seq analysis}

Three hybrids that were randomly chosen from each of the extremely tolerant/sensitives bulks were used for RNA-seq. In the salt and alkali stress treatments, root samples were collected at $0,2,4$, and 6 days after treatment. For the combined salt-alkali stress treatment, root samples were collected $0,1,2$, and 3 days after treatment, because under salt-alkali stress condition, the injury symptom appeared much early. Three plants of non-treated hybrids were also sampled as a control. Total RNA was extracted using a modified CTAB method [82]. An RNA-seq library was constructed using NEBNext Poly(A) mRNA Magnetic Isolation Module and NEBNext Ultra Directional RNA Library Prep Kit for Illumina (New England Biolabs) following the manufacturer's protocols. The library was sequenced (pairedend 150) with the Illumina HiSeq X Ten platform. The RNA-seq reads were mapped to the apple 'Golden Delicious' dihaploid GDDH genome with HISAT2 [83]. StringTie was used to assembly and quantify transcripts [84]. The co-expression network of the DEGs was analyzed using AppleMDO webtools [85].

\section{Gene relative expression assay}

Primers for real-time quantitative PCR (RT-qPCR) were designed and are listed in Table S25. RT-qPCR was performed using SYBR premix Ex Taq (TaKaRa) with an ABI7500 RT PCR system (Applied Biosystems). $\beta$-ACTI $\mathrm{N}$ was used as an internal reference.

\section{KASP genotyping, marker effect estimation, and GAP modeling}

Three hundred randomly chosen $\mathrm{F} 1$ hybrids from 'BC' $\times$ 'M9' were genotyped for each marker using the KASP assay (LGC Genomics, Beverly, MA, USA). The parents, 'BC' and 'M9,' were used as a control. The KASP primers were designed based on the $200 \mathrm{bp}$ sequence flanking the SNPs. The genotype data were output via 'SNP VIEWER' software (LGC). The genotype effect of a marker was estimated by subtracting the mean phenotype value of the population from the average phenotype value of individuals with a certain genotype. The marker effect was calculated by the absolute genotype effect deviation of a marker.

To develop GAP models, the GPV of a certain hybrid was estimated by adding the sum of genotype effects of 
all markers to the mean phenotype value of the population [86]. The GAP models were then subjected to fivefold cross validation $[42,67]$. The prediction accuracy of GAP models was determined by Pearson's correlation coefficients and linear regressions between GPV and OPV.

\section{Validation of genetic variations in candidate genes}

Genomic DNA was extracted from young leaves of the two parents using an improved CTAB method [87]. PCR was performed with high-fidelity Platinum TaqDNA Polymerase (Thermo Fisher Scientific), using specific primers for cloning promoter regions (Table S25). The PCR amplified fragments were sequenced by Invitrogen Biotechnology Co., Ltd. (Shanghai, http://www.invitrogen.com.cn). The sequences were mapped to the apple 'Golden Delicious' dihaploid GDDH genome and the loci showing variation were confirmed by sequence comparison.

\section{Generation of transgenic apple calli and salt, alkali, and salt-alkali treatments}

Agrobacterium tumefaciens EHA105 plasmid was transformed into 'Orin' apple callus following a previously published protocol [88]. 'Orin' apple callus was grown on an Murashige and Skoog medium containing $1.0 \mathrm{mg} /$ $\mathrm{L}$ 2,4-dichlorophenoxyacetic acid and $1.0 \mathrm{mg} / \mathrm{L} \mathrm{6-}$ benzylamino purine in the dark at $25^{\circ} \mathrm{C}$, and subcultured at $15 \mathrm{~d}$ intervals. A seven-day-old callus grown in a liquid medium was used transformed by infection with Agrobacterium for $10 \mathrm{~min}$ with gentle rotation at $25{ }^{\circ} \mathrm{C}$. After 2 days of co-cultivation with Agrobacterium, the callus was transferred to a subculture medium supplemented with $200 \mathrm{mg} / \mathrm{L}$ cefotaxime and $30 \mathrm{mg} / \mathrm{L}$ kanamycin for transgene selection. For the salt stress treatment, $\mathrm{NaCl}(100 \mathrm{mmol} / \mathrm{L})$ was added to the callus culture medium. $\mathrm{Na}_{2} \mathrm{CO}_{3}(\mathrm{pH}=9.0)$ was added to the culture medium for the alkali stress treatment. For the combined salt-alkali stress treatment $\mathrm{NaCl}+\mathrm{Na}_{2} \mathrm{CO}_{3}$ $(100 \mathrm{mmol} / \mathrm{L}, \mathrm{pH}=9.0)$ were added to the culture medium. The control consisted of the callus grown on culture medium without any additions [89]. Fourteen days after treatment, the fresh weight of the calli was weighed and the MDA content was assayed following a previously described method [90].

\section{Statistical analysis}

Data are shown with values expressed as means plus or minus standard deviations (SD). Statistical differences were determined using Student's t-tests. Differences were considered significant at $\left.P<0.05\left(^{*}\right), P<0.01{ }^{(* *}\right)$, and $P<0.0011^{(* * *)}$.

\section{Supplementary information}

Supplementary information accompanies this paper at https://doi.org/10. 1186/s12864-020-06961-9.

Additional file 1. Comparison in genomic DNA sequences of the upstream prior to the ATG codon of MdRGLG3 in apple rootstocks Malus robusta Rehd. 'Baleng Crab $(\mathrm{BC})$ ' $\times$ M. pumila Mill. 'M9'.

Additional file 2. Comparison in genomic DNA sequences of the upstream prior to the ATG codon of MdKCAB in apple rootstocks Malus robusta Rehd. 'Baleng Crab $(\mathrm{BC})^{\prime} \times$ M. pumila Mill. 'M9'.

Additional file 3: Supplementary Table S1. The phenotype data of alkali injury index (AID) of hybrids derived from 'Baleng Crab' (Malus robusta) $\times$ 'M9' (M. pumila) in 2015-2017. Supplementary Table S2. The phenotype data of salt injury index (SID) of hybrids derived from 'Baleng Crab' (Malus robusta) ×'M9' (M. pumila) in 2015-2017. Supplementary

Table S3. The phenotype data of salt-alkali injury index (SAID) of hybrids derived from 'Baleng Crab' (Malus robusta) × 'M9' (M. pumila) in 20162017. Supplementary Table S4. Phenotypes of extremity segregant bulks for injury indices of salt, alkali, and salt-alkali in hybrids derived from 'Baleng Crab' (Malus robusta) × 'M9' (M. pumila) Supplementary Table S5. Summary of the BSA-seq data in extremity bulks of tolerant and sensitive using hybrids derived from 'Baleng Crab' (Malus robusta) $\times$ 'M9' $(M$. pumila). Supplementary Table S6. Summary of QTLs for injury indices of salt, alkali, and salt-alkali identified via BSA-seq in hybrid population from 'Baleng Crab' (Malus robusta) $\times$ 'M9' (M. pumila). Supplementary

Table S7. Candidate genes for salt, alkali, and salt-alkali tolerance screened by parental re-sequencing, BSA-seq, and RNA-seq in a hybrid population from 'Baleng Crab' (Malus robusta) $\times$ 'M9' (M. pumila). Supplementary Table S8. Summary of candidate genes for salt, alkali, and saltalkali tolerance screened by parental re-sequencing, BSA-seq, and RNAseq in a hybrid population from 'Baleng Crab' (Malus robusta) $\times$ 'M9' (M. pumila). Supplementary Table S9. samples of root tissue for RNA-seq taken from salt, alkali, and salt-alkali treated hybrids from 'Baleng Crab' (Malus robusta) $\times$ 'M9' (M. pumila). Supplementary Table S10. Summary of the sequencing reads and reads mapping in RNA-seq.

Additional file 4: Supplementary Table S11. Sample correlation analysis of three biological replicates in RNA-seq. Supplementary Table S12. Differentially expressed genes (DEGs) detected by DESeq2 methods ( $F D R<0.05, \log 2 \mathrm{FC}>1$ or $\log 2 \mathrm{FC}<-1$, verticals represent normal genes. Up and down arrows represent up and down) in RNA-seq of salt. Supplementary Table S13. Differentially expressed genes (DEGs) detected by DESeq 2 methods (FDR $<0.05, \log 2 \mathrm{FC}>1$ or $\log 2 \mathrm{FC}<-1$, verticals represent normal genes. Up and down arrows represent up and down) in RNA-seq of alkali. Supplementary Table S14. Differentially expressed genes (DEGs) detected by DESeq2 methods (FDR $<0.05, \log 2 \mathrm{FC}>1$ or $\log 2 \mathrm{FC}<-1$, verticals represent normal genes. Up and down arrows represent up and down) in RNA-seq of salt-alkali. Supplementary Table S15. Co-expression network identified by AppleMDO analysis tools in hybrids tolerant or sensitive to salt, alkali, and salt-alkali treatments in hybrids from Malus robusta Rehd. 'Baleng Crab' × M. pumila Mill. 'M9'. Supplementary Table S16. Data for allelic variations of markers using for KASP assay in hybrids from 'Baleng Crab' (Malus robusta) ×'M9' (M. pumila). Supplementary Table S17. Estimates of marker genotype effects on salt, alkali, and salt-alkali injury indices in hybrids from 'Baleng Crab' (Malus robusta) $\times$ 'M9' (M. pumila). Supplementary Table S18. The marker genotypes, genomics predicted values (GPV), and observed phenotype values (OPV) of alkali injury index in $299 \mathrm{~F} 1$ hybrids from 'Baleng Crab' (Malus robusta) $\times$ 'M9' (M. pumila). Supplementary Table S19. The marker genotypes, genomics predicted values (GPV), and observed phenotype values (OPV) of salt injury index in $285 \mathrm{~F} 1$ hybrids from 'Baleng Crab' (Malus robusta) ×'M9' (M. pumila). Supplementary Table S20. The marker genotypes, genomics predicted values (GPV), and observed phenotype values (OPV) of saline-alkali injury index in 194 F1 hybrids from 'Baleng Crab' (Malus robusta) $\times$ 'M9' (M. pumila)

Additional file 5: Supplementary Table S21. The five-fold cross validation of genomics assisted prediction accuracy for injury indices of salt, alkali, and salt-alkali in F1 hybrids from 'Baleng Crab' (Malus robusta) $\times$ 'M9' (M. pumila). Supplementary Table S22. Linkage analysis of MdRGLG3 SNP168, SNP182, SNP932, and SNP936 with KASP marker on chromosome 
16 of alkali injury index. Supplementary Table S23. Linkage analysis of MdKCAB SNP11 and SNP761 with KASP marker on chromosome 16 of salt-alkali injury index. Supplementary Table S24. Genotypes of MdRGLG3 SNP168, SNP182, SNP932, and SNP936 in 100 Malus germplasm accessions. Supplementary Table S25. Primers of experimental validation in this study

Additional file 6: Fig. S1. Frequency distributions of salt (A), alkali (B), salt-alkali (C) injury indices in apple rootstock F1 hybrids of Malus robusta Rehd. 'Baleng Crab' $\times$ M. pumila Mill. 'M9' in 2015-2017.

Additional file 7: Fig. S2. Diagrams showing quantitative trait loci (QTLs) for salt injury index identified using bulked segregant analysis by sequencing in F1 hybrids of apple rootstocks Malus robusta Rehd. 'Baleng $\mathrm{Crab}(\mathrm{BC})^{\prime} \times M$. pumila Mill. 'M9'. Y-axis represents the $\mathrm{G}^{\prime}$ value, $\mathrm{X}$-axis represents chromosome physical position. The red curved lines: 'M9', blue curved lines: 'BC', black curved lines: 'BC' \& 'M9'. The horizontal lines with colors indicate the corresponding statistic significant threshold of $\mathrm{G}$ ' value.

Additional file 8: Fig. S3. Diagrams showing quantitative trait loci (QTLs) for alkali injury index identified using bulked segregant analysis by sequencing in $\mathrm{F} 1$ hybrids of apple rootstocks Malus robusta Rehd. 'Baleng Crab $(B C)^{\prime} \times M$. pumila Mill. 'M9'. Y-axis represents $G$ ' value, X-axis represents chromosome physical position. The red curved lines: 'M9', blue curved lines: 'BC', black curved lines: 'BC' \& 'M9'. The horizontal lines with colors indicate the corresponding statistic significant threshold of $\mathrm{G}$ ' value.

Additional file 9: Fig. S4. Diagrams showing quantitative trait loci (QTLs) for salt-alkali injury index identified using bulked segregant analysis by sequencing in F1 hybrids of apple rootstocks Malus robusta Rehd. 'Baleng Crab $(\mathrm{BC})^{\prime} \times M$. pumila Mill. 'M9'. Y-axis represents $G$ ' value, $X$-axis represents chromosome physical position. The red curved lines: 'M9', blue curved lines: 'BC', black curved lines: 'BC' \& 'M9'. The horizontal lines with colors indicate the corresponding statistic significant threshold of $\mathrm{G}$ value.

Additional file 10: Fig. S5. Sanger sequencing confirmed allelic variations in the coding region of MdRGLG3 between Malus robusta Rehd. 'Baleng Crab $(\mathrm{BC})$ ' $\times$ M. pumila Mill. 'M9'.

Additional file 11: Fig. S6. Dynamic changes in expression of MdRGLG3 (A) and MdKCAB (B) in salt, alkali and salt-alkali tolerant (T) or sensitive (S) hybrids of apple rootstocks Malus robusta Rehd. 'Baleng $\mathrm{Crab}^{\prime} \times$ M. pumila Mill. 'M9'. The gene expressions were shown in fragments per kilobase per million (FPKM) by RNA-seq and relative expression by qPCR.

Additional file 12: Fig. S7. Sanger sequencing confirmed allelic variations in the coding region of MdKCAB between Malus robusta Rehd. 'Baleng Crab $(\mathrm{BC})^{\prime} \times$ M. pumila Mill. 'M9'.

Additional file 13: Fig. S8. Differences in osmolality in nutrient solutions used for alkaline $\left(\mathrm{Na}_{2} \mathrm{CO}_{3}\right)$, saline $(\mathrm{NaCl})$, and alkaline-saline $(\mathrm{NaCl}$ $\left.+\mathrm{Na}_{2} \mathrm{CO}_{3}\right)$ stress treatments. Data are means of three biological replicates. Error bars indicate standard deviations. ${ }^{* *}$ and ${ }^{* * * *}$ indicate statistically significant differences at, $P<0.01$, and $P<0.0001$, respectively.

\section{Abbreviations}

ABA: Abscisic acid; AID: Alkali injury index; BSA-seq: Bulked segregant analysis via next generation resequencing; FPKM: Fragments per kilobase per million; GAP: Genomics-assisted prediction; GPV: Genomics predicted value; GS: Genomic selection; JA: Jasmonate; KASP: Kompetitive allele-specific PCR; MAS:: Marker assisted selection; MDA: Malondialdehyde; OPV: Observed phenotype value; qPCR:: Real-time quantitative PCR; QTLs: Quantitative trait Ioci; SA: Salicylate; SAID: Salt-alkali injury index; SID: Salt injury index; SNP: Single nucleotide polymorphism; WT: Wild type

\section{Acknowledgments}

The authors thank the Key Laboratory of Stress Physiology and Molecular Biology for Fruit. Trees in Beijing Municipality, the Key Laboratory of Biology and Genetic Improvement of Horticultural Crops (Nutrition and Physiology), Ministry of Agriculture, and the Construction of Beijing Science and Technology Innovation and Service Capacity in Top Subjects (CEFFPXM2019_014207_000032).

\section{Authors' contributions}

Z.H. and X.Z. initiated and designed the experiments. J.L., Y.X and H.F. performed salt, alkali and salt-alkali treatment, phenotypic investigation, and phenotypic analysis. J.L., Y.W., T.W., X.X., W.L., and C.Q. performed the molecular biology experiments. F.S. performed the bioinformatic analysis. J.L. and X.Z. wrote the paper. All authors have read and approved the manuscript.

\section{Funding}

This work was funded by the earmarked fund of the China Agriculture Research System (CARS-27).

\section{Availability of data and materials}

All RNA-seq reads, DNA re-sequencing reads and BSA-seq data are freely available and have been deposited in the NCBI Sequence Read Archive with the accession number PRJNA645374 (https://www.ncbi.nlm.nih.gov/sra/ ?term=PRJNA645374). The apple 'Golden Delicious' dihaploid GDDH genome (ftp://ftp.bioinfo.wsu.edu/species/Malus_X_domestica/Malus_X_domesticagenome_GDDH13_v1.1/assembly/) is also available at Genome Database for Rosaceae.

Ethics approval and consent to participate

Not applicable.

\section{Consent for publication}

Not applicable.

\section{Competing interests}

The authors declare that they have no competing interests.

Received: 24 February 2020 Accepted: 29 July 2020

Published online: 10 August 2020

\section{References}

1. Parida AK, Das AB. Salt tolerance and salinity effects on plants: a review. Ecotoxicol Environ Saf. 2005;60(3):324-49.

2. Munns R, James RA, Lauchli A. Approaches to increasing the salt tolerance of wheat and other cereals. J Exp Bot. 2006;57(5):1025-43.

3. Forni C, Duca D, Glick BR. Mechanisms of plant response to salt and drought stress and their alteration by rhizobacteria. Plant Soil. 2017;410(1-2): 335-56.

4. Campbell SA, Nishio JN. Iron deficiency studies of sugar beet using an improved sodium bicarbonate-buffered hydroponic growth system. J Plant Nutr. 2000;23(6):741-57.

5. Zhang ZS, Zhang LT, Gao HY, Jia YJ, Bu JW, Meng QW. Research of the photoinhibition of PSI and PSII in leaves of cucumber under chilling stress combined with different light intensities. Sci Agric Sin. 2009:42(12):4288-93.

6. Pang QY, Zhang AQ, Zang W, Wei L, Yan XF. Integrated proteomics and metabolomics for dissecting the mechanism of global responses to salt and alkali stress in Suaeda corniculata. Plant Soil. 2016;402(1-2):379-94.

7. Li R, Shi F, Fukuda K. Interactive effects of various salt and alkali stresses on growth, organic solutes, and cation accumulation in a halophyte Spartina alterniflora (Poaceae). Environ Exp Bot. 2010;68(1):66-74.

8. Guo R, Yang ZZ, Li F, Yan CR, Zhong XL, Liu Q, Xia X, Li HR, Zhao L. Comparative metabolic responses and adaptive strategies of wheat (Triticum aestivum) to salt and alkali stress. BMC Plant Biol. 2015;15(170):170.

9. Song $T$, $X u H H$, Sun $N$, Jiang L, Tian P, Yong $Y Y$, Yang WW, Cai H, Cui GW. Metabolomic analysis of alfalfa (Medicago sativa L.) root-symbiotic rhizobia responses under alkali stress. Frontiers in. Plant Sci. 2017;8:1208.

10. Yin ZP, Zhang $H$, Zhao Q, Yoo MJ, Zhu N, Yu JL, Yu JJ, Guo SY, Miao YC, Chen SX, Qin Z, Dai SJ. Physiological and comparative proteomic analyses of saline-alkali $\mathrm{NaHCO}_{3}$-responses in leaves of halophyte Puccinellia tenuiflora. Plant Soil. 2019;437(1-2):137-58.

11. Kawanabe S, Zhu TC. Degeneration and conservation of Aneurolepidium chinense grassland in northern China. Grassl Sci. 1991;37(1):91-9.

12. Shi DC, Sheng YM. Effect of various salt-alkaline mixed stress conditions on sunflower. Environ Environ Bot. 2005:54(1):8-21.

13. Peng YL, Gao ZW, Gao Y, Liu GF, Sheng LX, Wang DL. Eco-physiological characteristics of alfalfa seedlings in response to various mixed salt-alkaline stresses. J Integr Plant Biol. 2008;50(1):29-39. 
14. Yang CW, Wang P, Li CY, Shi DC, Wang DL. Comparison of effects of salt and alkali stresses on the growth and photosynthesis of wheat. Photosynthetica. 2008;46(1):107-14.

15. Qadir M, Tubeileh A, Akhtar J, Larbi A, Minhas PS, Khan MA. Productivity enhancement of salt-affected environments through crop diversification. Land Degrad Dev. 2008;19(4):429-53.

16. Jaiswal S, Gautam RK, Singh RK, Krishnamurthy SL, Ali S, Sakthivel K, lquebal MA, Anil R, Dinesh K. Harmonizing technological advances in phenomics and genomics for enhanced salt tolerance in rice from a practical perspective. Rice. 2019;12(1):89.

17. Akrami M, Arzani A. Inheritance of fruit yield and quality in melon (Cucumis melo L.) grown under field salinity stress. Sci Rep. 2019;9:7249.

18. Qi DL, Guo GZ, Lee MC, Zhang JG, Cao GL, Zhang SY, Suh SC, Zhou QY, Han LZ. Identifification of quantitative trait loci for the dead leaf rate and the seedling dead rate under alkaline stress in rice. J Genet Genomics. 2008; 35:299-305.

19. Wang ZF, Cheng JP, Chen ZW, Huang J, Bao YM, Wang JF, Zhang HS Identification of QTLs with main, epistatic and QTL $\times$ environment interaction effects for salt tolerance in rice seedlings under different salinity conditions. Theor Appl Genet. 2012;125(4):807-15.

20. Liang YP, Sun J, Suo YN, Liu HL, Wang JG, Zheng HL, Sun XX, Zou DT. QTL mapping and $\mathrm{QTL}^{*}$ environment interaction analysis of salt and alkali tolerance-related traits in rice (Oryza sativa L.). Sci Agric Sin. 2017;50(10): 1747-62.

21. Diouf L, Zhaoe P, He SP, Gong WF, Magwanga RO, Du XM. QTL mapping for salt tolerance in an intra-specific upland cotton at seedling stage using SSR markers. J Plant Breed Genet. 2017;5(2):57-73.

22. Kumawat KR, Gothwal DK. Genetic variability for seedling characters in lentil under salinity stress. Electron J Plant Breed. 2018;9(4):1295-302.

23. Diouf IA, Derivot L, Bitton F, Pascual L, Causse M. Water deficit and salinity stress reveal many specific QTL for plant growth and fruit quality traits in tomato. Front Plant Sci. 2018;9:279.

24. Quesada V, Garcia-Martinez S, Piqueras P, Ponce MR, Micol JL. Genetic architecture of $\mathrm{NaCl}$ tolerance in Arabidopsis. Plant Physiol. 2002;130(2):95163.

25. Takehisa H, Shimodate T, Fukuta Y, Ueda T, Yano M, Yamaya T, Kameya T, Sato T. Identification of quantitative trait loci for plant growth of rice in paddy field flooded with salt water. Field Crop Res. 2004;89(1):85-95.

26. Villalta I, Reina-Sanchez A, Bolarin MC, Cuartero J, Belver A, Venema K, Carbonell EA, Asins MJ. Genetic analysis of $\mathrm{Na}^{+}$and $\mathrm{K}^{+}$concentrations in leaf and stem as physiological components of salt tolerance in tomato. Theor Appl Genet. 2008;116(6):869-80.

27. Oluoch G, Zheng JY, Wang XX, Khan MKR, Zhou ZL, Cai XY, Wang CY, Wang YH, Li XY, Wang H, Liu F, Wang KB. QTL mapping for salt tolerance at seedling stage in the interspecific cross of Gossypium tomentosum with Gossypium hirsutum. Euphytica. 2016;209:223-35.

28. Tuyen DD, Zhang HM, Xu DH. Validation and high-resolution mapping of a major quantitative trait locus for alkaline salt tolerance in soybean using residual heterozygous line. Mol Breed. 2013;31(1):79-86.

29. Sun J, Xie DW, Zhang EY, Zheng HL, Wang JG, Liu HL, Yang LM, Zhang SL, Wang L, Zou DT. QTL mapping of photosynthetic-related traits in rice under salt and alkali stresses. Euphytica. 2019;215(9):147.

30. Negrao S, Almadanim MC, Pires IS, Abreu IA, Maroco J, Courtois B, Gregorio $\mathrm{GB}, \mathrm{McNally} \mathrm{KL}$, Oliveira MM. New allelic variants found in key rice salttolerance genes: An association study. Plant Biotechnol J. 2013;11(1):87-100.

31. Jain M, Moharana KC, Shankar R, Kumari R, Garg R. Genome wide discovery of DNA polymorphisms in rice cultivars with contrasting drought and salinity stress response and their functional relevance. Plant Biotechnol J. 2014;12(2):253-64.

32. Rahman MA, Thomson MJ, Shah-E-Alam M, De Ocampo M, Egdane J, Ismail AM. Exploring novel genetic sources of salinity tolerance in rice through molecular and physiological characterization. Ann Bot. 2016;117(6):1083-97.

33. Tiwari S, SI K, Kumar V, Singh B, Rao AR, Sv AM, Rai V, Singh AK, Singh NK. Mapping QTLs for salt tolerance in rice (Oryza sativa L.) by bulked segregant analysis of recombinant inbred lines using 50K SNP chip. PLoS One. 2016; 11(4):e0153610.

34. Mishra S, Singh B, Panda K, Singh BP, Singh N, Misra P, Rai V, Singh NK. Association of SNP haplotypes of HKT family genes with salt tolerance in Indian wild rice germplasm. Rice. 2016;9:15.

35. Cui YP, Ma JJ, Liu GY, Wang NH, Pei WF, Wu M, Li XL, Zhang JF, Yu JW. Genome-wide identification, sequence variation, and expression of the glycerol-3-phosphate acyltransferase (GPAT) gene family in Gossypium. Front Genet. 2019;10:116.

36. Wang JP, Li RZ, Mao XG, Jing RL. Functional analysis and marker development of TaCRT-D gene in common wheat (Triticum aestivum L.). Frontiers in. Plant Sci. 2017;8:1557.

37. Kainer D, Lanfear R, Foley WJ, Kulheim C. Genomic approaches to selection in outcrossing perennials: focus on essential oil crops. Theor Appl Genet. 2015;128(12):2351-65.

38. Werner CR, Voss-Fels KP, Miller CN, Qian W, Hua W, Guan C-Y, Snowdon RJ, Qian L. Effective genomic selection in a narrow-gene pool crop with lowdensity markers: Asian rapeseed as an example. Plant Genome. 2018;11(2): 170084.

39. Meuwissen T. Genomic selection: marker assisted selection on a genome wide scale. J Anim Breed Genet. 2007;124:321-2.

40. Goddard ME, Hayes BJ, Meuwissen THE. Using the genomic relationship matrix to predict the accuracy of genomic selection. J Anim Breed Genet. 2011;128(6):409-21.

41. Fikere M, Barbulescu DM, Malmberg MM, Shi F, Koh JCO, Slater AT, MacLeod IM, Bowman PJ, Salisbury PA, Spangenberg GC, Cogan NOI, Daetwyler HD. Genomic prediction using prior quantitative trait loci information reveals a large reservoir of underutilised blackleg resistance in diverse canola (Brassica napus L.) Lines. Plant Genome. 2018;11(2):170100.

42. Kumar S, Chagne D, Bink M, Volz R, Whitworth C, Carlisle C. Genomic selection for fruit quality traits in apple (Malus domestica Borkh.). PLoS One. 2012;7(5):e36674.

43. Shen F, Huang ZY, Zhang BG, Wang Y, Zhang X, Wu T, Xu XF, Zhang XZ, Han $Z$ ZH. Mapping gene markers for apple fruit ring rot disease resistance using a multi- omics approach. G3: Genes Genomes Genet. 2019;9(5):166378.

44. Qu YP. Identification of quantitative trait loci for salt and alkaline tolerance in rice. Master thesis. Beijing: Chinese Academy of Agricultural Sciences; 2007. .

45. Chen HT, Jiang H, Yan MX, Dong GJ, Qian Q, Guo LB. QTL-mapping comparison of tolerance to alkali at germination period and early seeding stage between two different double haploid populations in rice. Mol Plant Breed. 2008;6:439-50.

46. Usadel B, Obayashi T, Mutwil M, Giorgi FM, Bassel GW, Tanimoto M, Chow A, Steinhauser D, Persson S, Provart NJ. Co-expression tools for plant biology: opportunities for hypothesis generation and caveats. Plant Cell Environ. 2009;32(2):1633-51.

47. Rohilla P, Yadav JP. Acute salt stress differentially modulates nitrate reductase expression in contrasting salt responsive rice cultivars. Protoplasma. 2019;256(5):1267-78.

48. Xiao CX, Cui XL, Lu HY, Han L, Liu SB, Zheng YX, Wang H, Wang H, Yang CW. Comparative adaptive strategies of old and young leaves to alkali-stress in hexaploid wheat. Environ Exp Bot. 2020;171:103955.

49. Lopez-Molina L, Mongrand S, Chua NH. A postgermination developmental arrest checkpoint is mediated by abscisic acid and requires the ABI5 transcription factor in Arabidopsis. Proc Natl Acad Sci U S A. 2001;98(8): 4782-7.

50. Varet A, Parker J, Tornero P, Nass N, Nurnberger T, Dangl JL, Scheel D, Lee J. NHL25 and NHL3, two NDR1/HIN1-like genes in Arabidopsis thaliana with potential role(s) in plant defense. Mol Plant Microbe Interact. 2002;15(6): 608-16.

51. Liu WJ, Wang YC, Gao CQ. The ethylene response factor (ERF) genes from Tamarix hispida respond to salt, drought and ABA treatment. Trees-structure Funct. 2014;28(2):317-27.

52. Scharf KD, Berberich T, Ebersberger I, Nover L. The plant heat stress transcription factor (Hsf) family: structure, function and evolution. Biochim Biophys Acta-Gene Regul Mech. 2012;1861(1):60.

53. Albihlal WS, Obomighie I, Blein T, Persad R, Chernukhin I, Crespi M, Bechtold U, Mullineaux PM. Arabidopsis HEAT SHOCK TRANSCRIPTION FACTORA1b regulates multiple developmental genes under benign and stress conditions. J Exp Bot. 2018;69(11):2847-62.

54. Andrasi N, Rigo G, Zsigmond L, Perez-Salamo I, Papdi C, Klement E, PettkoSzandtner A, Baba Al, Ayaydin F, Dasari R, Cseplo A, Szabados L. The mitogen-activated protein kinase 4-phosphorylated heat shock factor A4A regulates responses to combined salt and heat stresses. J Exp Bot. 2019; 70(18):4903-17.

55. Pérez-Salamó I, Papdi C, Rigó G, Zsigmond L, Vilela B, Lumbreras V, Nagy I, Horvath B, Domoki M, Darula Z, Medzihradszky K, Bogre L, Koncz C, 
Szabados $L$. The heat shock factor A4A confers salt tolerance and is regulated by oxidative stress and the mitogenactivated protein kinases MPK3 and MPK6. Plant Physiol. 2014;165:319-34.

56. Kang M, Lee S, Abdelmageed H, Reichert A, Lee HK, Fokar M, Mysore KS, Allen RD. Arabidopsis stress associated protein 9 mediates biotic and abiotic stress responsive ABA signaling via the proteasome pathway. Plant Cell Environ. 2017:40(5):702-16.

57. Zhou YP, Duan J, Fujibe T, Yamamoto KT, Tian CE. AtIQM1, a novel calmodulin-binding protein, is involved in stomatal movement in Arabidopsis. Plant Mol Biol. 2012;79(4-5):333-46.

58. Hasegawa PM, Bressan RA, Zhu JK, Bohnert HJ. Plant cellular and molecular responses to high salt. Annu Rev Plant Physiol Plant Mol Biol. 2000;51:46399.

59. Liu XL, Zhang H, Jin YY, Wang MM, Yang HY, Ma HY, Jiang CJ, Liang ZW. Abscisic acid primes rice seedlings for enhanced tolerance to alkaline stress by upregulating antioxidant defense and stress tolerance-related genes. Plant Soil. 2019;438(1-2):39-55.

60. Boudsocq M, Droillard MJ, Barbier-Brygoo H, Lauriere C. Different phosphorylation mechanisms are involved in the activation of sucrose nonfermenting 1 related protein kinases 2 by osmotic stresses and abscisic acid. Plant Mol Biol. 2007;63:491-503.

61. Zhang H, Mao X, Jing R, Chang X, Xie H. Characterization of a common wheat (Triticum aestivum L.)TaSnRK2.7 gene involved in abiotic stress responses. J Exp Bot. 2011;62(3):975-88.

62. Zhang H, Li W, Mao X, Jing R, Jia H. Differential activation of the wheat SnRK2 family by abiotic stresses. Front Plant Sci. 2016;7:420.

63. Hazman M, Hause B, Eiche E, Nick P, Riemann M. Increased tolerance to salt stress in OPDA-deficient rice ALLENE OXIDE CYCLASE mutants is linked to an increased ROS-scavenging activity. J Exp Bot. 2015;66(11):3339-52.

64. Li W, Guan Q, Wang ZY, Wang Y, Zhu J. A bi-functional xyloglucan galactosyltransferase is an indispensable salt stress tolerance determinant in Arabidopsis. Mol Plant. 2013;6(4):1344-54.

65. Muranty H, Troggio M, Sadok IB, Rifai MI, Auwerkerken A, Banchi E, Velasco R, Stevanato P, van de Weg WE, Di Guardo M, Kumar S, Laurens F, Bink MCAM. Accuracy and responses of genomic selection on key traits in apple breeding. Horticulture Res. 2015;2:15060,

66. McClure KA, Gardner KM, Douglas GM, Song J, Forney CF, DeLong J, Fan L, Du L, Toivonen PMA, Somers DJ, Rajcan I, Myles S. A genome-wide association study of apple quality and scab resistance. Plant Genome. 2018; 11(1):170075.

67. Abed A, Perez-Rodriguez P, Crossa J, Belzile F. When less can be better: how can we make genomic selection more cost-effective and accurate in barley? Theor Appl Genet. 2018;131(9):1873-90.

68. Peace CP, Bianco L, Troggio M, van de Weg E, Howard NP, Cornille A, Durel C-E, Myles S, Migicovsky Z, Schaffer RJ, Costes E, Fazio G, Yamane H, van Nocker S, Gottschalk C, Costa F, Chagné D, Zhang X, Patocchi A, Gardiner SE, Hardner C, Kumar S, Laurens F, Bucher E, Main D, Jung S, Vanderzande S. Apple whole genome sequences: recent advances and new prospects. Horticulture Res. 2019;6:59.

69. Wang YY, Mopper S, Hasenstein KH. Effects of salinity on endogenous ABA, IAA, JA and SA in Iris hexagona. J Chem Ecol. 2001;27(2):327-42.

70. Anderson JP, Badruzsaufari E, Schenk PM, Manners JM, Desmond OJ, Ehlert C, Maclean DJ, Ebert PR, Kazan K. Antagonistic interaction between abscisic acid and jasmonate-ethylene signaling pathways modulates defense gene expression and disease resistance in Arabidopsis. Plant Cell. 2004;16(12): 3460-79.

71. Sawada H, Shim IS, Usui K. Induction of benzoic acid 2-hydroxylase and salicylic acid biosynthesis-modulation by salt stress in rice seedling. Plant Sci. 2006;171(2):263-70.

72. Zhang X, Wu Q, Ren J, Qian WQ, He SP, Huang KW, Yu XC, Gao Y, Huang P, An CC. Two novel RING-type ubiquitin ligases, RGLG3 and RGLG4, are essential for jasmonate-mediated responses in Arabidopsis. Plant Physiol. 2012;160(2):808-22.

73. Zhang X, Wu Q, An CC. RGLG3 and RGLG4, novel ubiquitin ligases modulating jasmonate signaling. Plant Signal Behav. 2012;7(12):1709-11.

74. Tian S, Liu W, Wu Y, Rafi H, Segal AS, Desir GV. Regulation of the voltagegated K+ channel KCNA10 by KCNA4B, a novel -subunit. Am J Physiol Renal Physiol. 2002;283(1):142-9.

75. Jegla T, Busey G, Assmann SM. Evolution and structural characteristics of plant voltage-gated K+ channels. Plant Cell. 2018;30(12):2898-909.
76. Fu MY, Li C, Ma FW. Physiological responses and tolerance to $\mathrm{NaCl}$ stress in different biotypes of Malus prunifolia. Euphytica. 2013;189(1):101-9.

77. Feng Y, Liu J, Zhai LM, Gan ZY, Zhang GF, Yang SH, Wang Y, Wu T, Zhang $X Z, X u X F$, Han ZH. Natural variation in cytokinin maintenance improves salt tolerance in apple rootstocks. Plant Cell Environ. 2018;42(2):424-36.

78. Li H, Zhan XC, Wei GC, Yu L, Li CR. Measurement of osmotic pressure of drug solution with hygrometer. West China J Pharmaceutial Sci. 2012;27(5): $552-4$.

79. Li H, Durbin R. Fast and accurate short read alignment with burrowswheeler transform. Bioinformatics. 2010;26(5):589-95.

80. Daccord N, Celton JM, Linsmith G, Becker C, Choisne N, Schijlen E, van de Geest H, Bianco L, Micheletti D, Velasco R, Di Pierro EA, Gouzy J, Rees DJG, Guerif P, Muranty H, Durel CE, Laurens F, Lespinasse Y, Gaillard S, Aubourg S, Quesneville H, Weigel D, van de Weg E, Troggio M, Bucher E. High-quality de novo assembly of the apple genome and methylome dynamics of early fruit development. Nat Genet. 2017;49(7):1099-106.

81. Magwene PM, Willis JH, Kelly JK. The statistics of bulk segregant analysis using next generation sequencing. PLoS Comput Biol. 2011;7(11):e1002255.

82. Moser C, Gatto P, Moser M, Pindo M, Velasco R. Isolation of functional RNA from small amounts of different grape and apple tissues. Mol Biotechnol. 2004;26(2):95-9.

83. Kim D, Langmead B, Salzberg SL. HISAT: a fast spliced aligner with low memory requirements. Nat Methods. 2015;12(4):357-60.

84. Pertea M, Pertea GM, Antonescu CM, Chang TC, Mendell JT, Salzberg SL. StringTie enables improved reconstruction of a transcriptome from RNA-seq reads. Nat Biotechnol. 2015;33(3):290-5.

85. Da LL, Liu Y, Yang JT, Tian T, She JJ, Ma XL, Xu WY, Su Z. AppleMDO: a multi-dimensional omics database for apple co-expression network and chromatin states. Front Plant Sci. 2019;10:1333.

86. Jia DJ, Shen F, Wang Y, Wu T, Xu XF, Zhang XZ, Han ZH. Apple fruit acidity is genetically diversified by natural variations in three hierarchical epistatic genes MdSAUR37, MdPP2CH and MdALMTII. Plant J. 2018;95(3):427-43.

87. Porebski S, Bailey LG, Baum BR. Modification of a CTAB DNA extraction protocol for plants containing high polysaccharide and polyphenol components. Plant Mol Biol Report. 1997;15(1):8-15.

88. Zhang XR, Henriques R, Lin SS, Niu QW, Chua NH. Agrobacterium-mediated transformation of Arabidopsis thaliana using the floral dip method. Nat Protoc. 2006;1(2):641-6.

89. Wang $P$, Sun $X$, Jia X, Ma FW. Apple autophagy-related protein MdATG3s afford tolerance to multiple abiotic stresses. Plant Sci. 2017; 256:53-64.

90. Sun MH, Ma QJ, Hu DG, Zhu XP, You CX, Shu HR, Hao YJ. The glucose sensor MdHXK1 phosphorylates a tonoplast $\mathrm{Na}+$ / $\mathrm{H}+$ exchanger to improve salt tolerance. Plant Physiol. 2018;176(4):2977-90.

\section{Publisher's Note}

Springer Nature remains neutral with regard to jurisdictional claims in published maps and institutional affiliations.

\section{Ready to submit your research? Choose BMC and benefit from:}

- fast, convenient online submission

- thorough peer review by experienced researchers in your field

- rapid publication on acceptance

- support for research data, including large and complex data types

- gold Open Access which fosters wider collaboration and increased citations

- maximum visibility for your research: over $100 \mathrm{M}$ website views per year

At $\mathrm{BMC}$, research is always in progress.

Learn more biomedcentral.com/submissions 